\author{
UNIVERSIDADE DE SÃO PAULO \\ INSTITUTO DE RELAÇÕES INTERNACIONAIS \\ PROGRAMA DE PÓS-GRADUAÇÃO EM RELAÇÕES \\ INTERNACIONAIS
}

MATHEUS SOLDI HARDT

\title{
OS DETERMINANTES QUE INFLUENCIAM NA ADESÃO AOS REGIMES INTERNACIONAIS DE DIREITOS HUMANOS
}

São Paulo

2014 


\author{
UNIVERSIDADE DE SÃO PAULO \\ INSTITUTO DE RELAÇÕES INTERNACIONAIS \\ PROGRAMA DE PÓS-GRADUAÇÃO EM RELAÇÕES \\ INTERNACIONAIS
}

\title{
OS DETERMINANTES QUE INFLUENCIAM NA ADESÃO AOS REGIMES INTERNACIONAIS DE DIREITOS HUMANOS
}

MATHEUS SOLDI HARDT

Dissertação apresentada ao Programa de
Pós-Graduação em

Orientador(a): Profa. Dra. Janina Onuki

São Paulo

2014 


\section{Sumário}

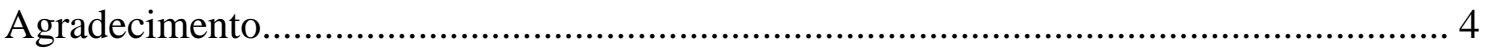

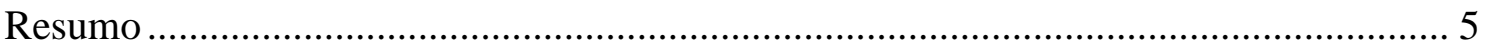

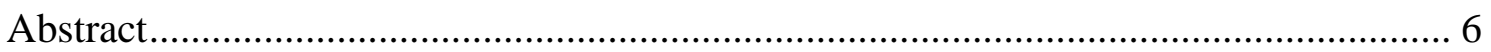

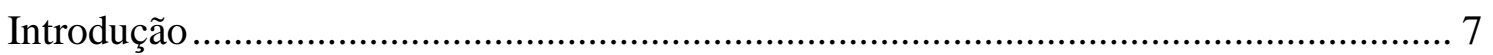

Artigo I: Evolução histórica dos estudos sobre regimes internacionais ......................... 9

Interesse Estatal e adesão a regimes internacionais .................................................. 9

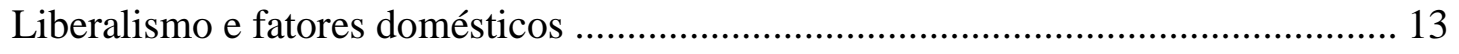

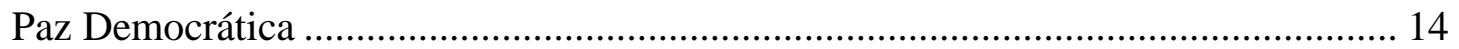

Adesão aos tratados internacionais de Direitos Humanos .............................................. 16

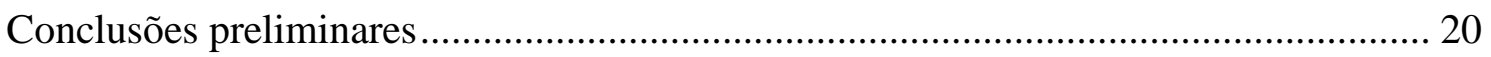

Os Determinantes Que Influenciam Na Adesão Aos Regimes Internacionais De Direitos Humanos: Uma Análise Empírica .................................................................................. 22

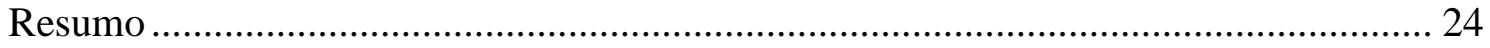

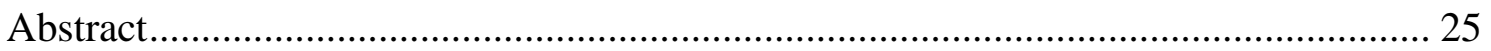

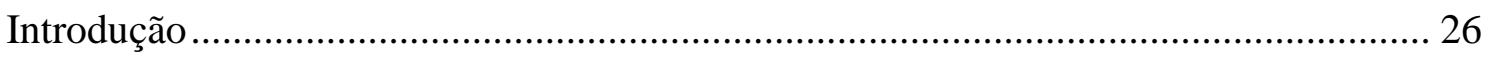

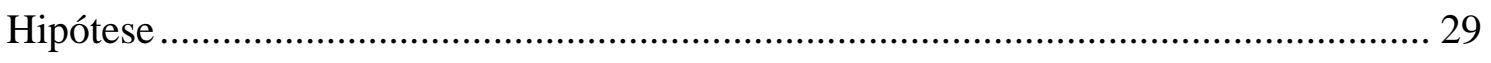

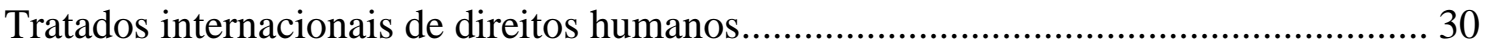

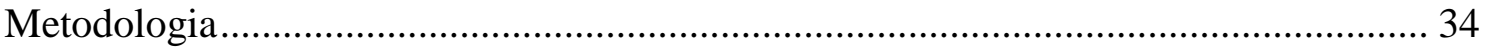

Velocidade de adesão aos regimes de direitos humanos ............................................... 37

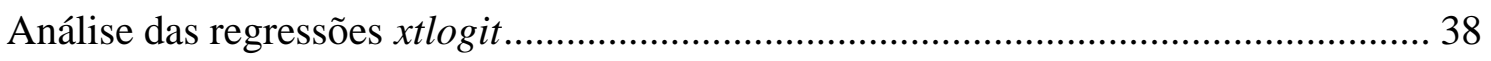

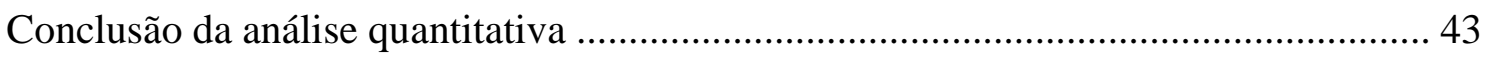

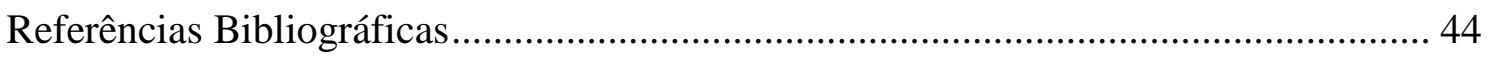

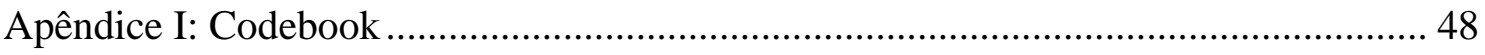

Apêndice II - Sumário do Banco de Dados .................................................................. 52 


\section{Agradecimento}

AgradeÇo À CAPES, Aos MeUs PAis, Ao Pedro e ESPECIALMENTE Ao RAPHAEL, 


\section{Resumo}

O estudo de adesão a regimes internacionais se desenvolveu na década de 1990 e a partir de então seu crescimento se deu majoritariamente no campo empírico, principalmente nos estudos sobre regimes de direitos humanos. No entanto, sua fundamentação teórica permanece nas teorias clássicas de Relações Internacionais. Portanto, antes de apresentarmos em quais circunstâncias político-sociais que levam um país a aderir um regime de direitos humanos. Iremos primeiro discorrer sobre a fundamentação teórica das análises sobre adesão aos regimes internacionais, notadamente os de direitos humanos. Isso porque, a depender da linha teórica que se segue, a adesão aos tratados internacionais ocorre por diferentes interesses e por pressão de grupos políticos ou civis diversos. Essas interpretações abrangem um espectro amplo, partindo do realismo ao idealismo, passando pelo teoria crítica e construtivismo, entre outras. Enquanto os realistas argumentam que a adesão a um tratado internacional ocorre pela pressão de um Estado hegemônico. As análises liberais sobre adesão se desenvolveram com um foco nas características domésticas dos Estados. Um braço investigativo que surgiu a partir dos estudos liberais foi a agenda de pesquisa da Paz Democrática (Democratic Peace - DP). Com base nestas teorias seria interessante examinar quais são os determinantes que influenciam a adesão aos regimes internacionais de direitos humanos. Assim seria possível estabelecer uma relação causal entre as variáveis independentes e a adesão ao tratado - variável dependente. No próximo artigo tentaremos avançar com essa agenda de pesquisa.

Adesão à regimes, Direitos Humanos, Realismo, Idealismo, Paz Democrática 


\begin{abstract}
The studies of accession to international regimes developed in the 1990s and since then its growth was mainly in the empirical field, especially in studies on human rights regimes. However, its theoretical foundation remains in the classical theories of International Relations. Therefore, before presenting in which political and social circumstances that lead a country to join a human rights regime. We will first discuss the theoretical basis of the analysis of accession to international regimes, notably those on human rights. This is because, depending on the theoretical argument that follows, accession to international treaties occurs for different interests and pressure from politicians or various civic groups. These interpretations cover a broad spectrum, starting from realism to idealism, through the critical theory and constructivism, among others. While realists argue that accession to an international treaty takes place by the pressure of a hegemonic State. The liberal analyzes of accession developed with a focus on domestic characteristics of the State. An investigative agenda that came from the liberal studies was the research agenda of the Democratic Peace. Based on these theories, it would be interesting to examine what are the determinants that influence accession to international human rights regimes. Therefore, it would be possible to establish a causal relationship between the independent variables and accession to the treaty - dependent variable. In the next paper, we will try to move forward with this research agenda.
\end{abstract}

Accession to International Regimes, Human Rights, Realism, Idealism, Democratic Peace 


\section{Introdução}

O estudo de adesão a regimes internacionais se desenvolveu na década de 1990 e a partir de então seu crescimento se deu majoritariamente no campo empírico, principalmente nos estudos sobre regimes de direitos humanos ${ }^{1}$. Segundo Simmons (2010), graças aos esforços de organizações internacionais, tanto estatais quanto não governamentais, de grupos de estudos e de agências governamentais, atualmente, os dados empíricos para as análises quantitativas são mais extensos e mais informativos do que nos anos anteriores. Para além dessa constatação, Simmons (2010) aponta que quanto mais o campo de estudo de adesão aos regimes internacionais amadurece, mais os estudos tendem a analisar os aspectos domésticos que levaram à adesão de uma norma internacional e quais as implicações políticas de seguir ou não um determinado regime. Movendo, dessa forma, de uma análise estato-cêntrica sobre adesão para um modelo que abarca a influência dos atores não estatais nesta área.

Tendo em vista esse panorama geral, esta dissertação de mestrado pretende analisar quais as circunstâncias político-sociais que levam um país a aderir a um regime de direitos humanos, no período de 1966 a 2012. Com uma metodologia quantitativa tentaremos apontar quais fatores e sob quais situações os incentivos para a adesão são gerados. Também analisaremos como as democracias de terceira onda em diante (HUNTINGTON, 1991), denominadas novas democracias, se comportam no que se refere à adesão aos regimes de direitos humanos. ${ }^{2}$ Observar no estudo quantitativo esse grupo de países justifica-se pelo fato de eles terem um comportamento próprio quando se trata de aderir a regimes de direitos humanos. Esse dado foi levantado por Landman (2005), que desconfiou que houvesse níveis de adesão diferentes a depender da natureza do regime governamental. Segundo Landman, as democracias aderem mais rapidamente do que as autocracias aos regimes de direitos humanos, e as democracias de terceira onda

\footnotetext{
${ }^{1}$ Os regimes internacionais de direitos humanos têm aspectos peculiares se comparados aos regimes internacionais de segurança, de comércio e de meio-ambiente (BAYEFSKY, 2001; HATHAWAY, 2002, 2007). Isso porque ao contrário destes últimos os regimes internacionais de direitos humanos não visam prevenir disputas externas às fronteiras do Estado, mas sim garantir um tratamento digno e humano aos cidadãos. Portanto, como os Estados geralmente possuem baixo interesse no tipo de tratamento que cidadãos estrangeiros recebem em seus Estados de origem, o conceito de reciprocidade acaba não se aplicando a essa área, diminuindo os benefícios de um acordo mútuo entre Estados.

${ }^{2}$ De acordo com Huntington (1991), a terceira onda de democracia teve início em 1974 com a Revolução dos Cravos em Portugal, pondo fim ao regime ditatorial do Estado Novo vigente desde 1933. Desde essa revolução, dezenas de outros Estados passaram por transições democráticas (mais de 30 países), mais que dobrando o número de democracias no mundo.
} 
em diante aderem mais prontamente e com menos reservas do que as democracias consolidadas.

Com o período de análise definido, as variáveis independentes que serão examinadas para verificar sob quais circunstâncias o Estado adere aos regimes de direitos humanos são: se o país é ou não uma nova democracia; o índice dos direitos da integridade física (CIRI Physical Integrity Rights Index); a região do país; a orientação política (esquerda ou direita) do governo de situação, entre outras variáveis. Por fim, cinco regimes de direitos humanos serão analisados: o Pacto Internacional dos Direitos Econômicos, Sociais e Culturais de 1966, o Pacto Internacional de Direitos Civis e Políticos de 1966, a Convenção sobre a Eliminação de Todas as Formas de Discriminação contra a Mulher (CEDAW) de 1979, a Convenção contra a tortura e outros tratamentos ou penas cruéis, desumanos ou degradantes (1984) e a Convenção do Direito das Crianças de 1989.

A relevância deste estudo está em verificar em quais circunstâncias estes dois campos de estudos sobre adesão de tratados internacionais de direitos humanos, que até então estão descolados, são válidos: o primeiro deles aponta que as elites políticas democráticas aderem a regimes de direitos humanos para assegurar que as atrocidades cometidas pelos regimes ditatoriais não ocorram no futuro (MORAVCSIK, 2000; MANSFIELD \& PEVEHOUSE, 2006; 2008; HAFNER-BURTON et al, 2008). A segunda corrente afirma que a pressão para a adesão a esse tipo de tratado é bottom-up e tem origem nos movimentos sociais e ONGs nacionais inseridas em uma rede transnacional de ONGs, estabelecidas principalmente em democracias consolidas (BRYSK, 1993; KECK \& SIKKINK, 1998; RISSE et al., 1999; WIIK, 2002; CARDENAS, 2004; 2008; NEUMAYER, 2005; FRANKLIN, 2008; SIMMONS, 2009).

Enfim, esta dissertação de mestrado está estruturada da seguinte forma, em um primeiro artigo, apresentaremos a evolução das teorias de relações internacionais e como elas trabalham com o tema de regimes e tratados internacionais. Essa primeira parte é importante por delinear os principais embates teóricos que existem e quais são as variáveis relevantes a serem observadas na parte empírica. Em seguida, em um segundo artigo, exporemos o modelo quantitativo, que visa entender quais são os determinantes domésticos e internacionais que influenciam na adesão aos tratados e regimes internacionais. 


\section{Artigo I: Evolução histórica dos estudos sobre regimes internacionais}

A depender da linha teórica que se segue, a adesão aos tratados internacionais ocorre por diferentes interesses e por pressão de grupos políticos ou civis diversos. Essas interpretações abrangem um espectro amplo, partindo do realismo ao idealismo, passando pelo teoria crítica e construtivismo, entre outras. Nesta seção analisaremos as principais abordagens teóricas para entendermos melhor quais são os mecanismos que afetam a adesão a regimes internacionais e como eles agem. Por fim, escolheremos a teoria Liberal Republicana e da Paz Democrática para analisarmos quais são os determinantes que influenciam na adesão aos tratados internacionais de direitos humanos.

\section{Interesse Estatal e adesão a regimes internacionais}

Alguns teóricos postulam que a adesão a um tratado internacional ocorre pela pressão de um Estado hegemônico. Dentre esses marcos teóricos estão três correntes realistas ${ }^{3}$ de relações internacionais, que examinaremos a seguir. A primeira onda de realistas buscava compreender a relação entre a ascensão e queda econômica de uma nação e sua respectiva importância militar no período. Assim sendo, a analogia que esses primeiros teóricos buscavam estabelecer era entre a variável econômica e a militar. Nesse sentido, a adesão a um tratado internacional estaria relacionada com a capacidade de um Estado hegemônico, militar ou economicamente, em pressionar outros Estados a ratificar uma norma internacional.

Já a segunda onda de realistas procurou entender como a mudança no poder relativo gera uma mudança na política externa. Essa preocupação sutil os diferencia dos teóricos da primeira geração, uma vez que estes não se preocupavam com a possibilidade, muito menos com o processo, de perda ou ganho de poder no plano internacional. Um exemplo da pesquisa feita por teóricos da segunda onda realista é o estudo de caso de Friedberg (1988) sobre a ascensão e queda da Inglaterra. Nessa obra, o autor busca entender em que

\footnotetext{
${ }^{3}$ Os teóricos realistas argumentam que as relações entre Estados ocorrem pela lógica de soma-zero (o ganho de um ator, inexoravelmente, decorre da perda de poder de outro ator). Essa lógica aplicada a estrutura do sistema internacional promove uma busca incessante por poder, resultando no aumento de conflitos armados e limitando os possíveis ganhos decorrentes das trocas comerciais (MEARSHEIMER, 2007). Partindo de um outro ponto de vista, do neorealismo defensivo, Kenneth Waltz $(1979 ; 1986)$ sustenta que a preocupação central do Estado é com sua própria sobrevivência no plano internacional. Consequentemente, o sistema tenderia ao equilíbrio, pois os países estariam mais preocupados com sua autopreservação do que com a expansão do seu poder.
} 
momento o declínio militar britânico começou a afetar o comportamento externo do país. Ao analisar este caso, Friedberg observou que as decisões tomadas pelos britânicos durante o período de declínio militar não eram racionais. Isso ficava evidente, uma vez que os tomadores de decisão ingleses muitas vezes ao agirem ignoravam a crescente incapacidade militar ou ao tentarem corrigir alguns defeitos da política externa, acabavam por criar novos e mais perigosos problemas. Para explicar a postura irracional dos atores no plano internacional, Friedberg teve que encontrar fatores domésticos para além da capacidade relativa. Assim sendo, fatores institucionais, organizacionais e da política doméstica foram adicionados à análise. ${ }^{4}$ Dessa forma, para os teóricos dessa corrente, a adesão a um tratado pode ser influenciada erroneamente por um hegemon em declínio, que posteriormente não terá capacidade de enforcement, ou por um país que está com seu poder relativo mundial em ascensão.

Por fim, dentro da corrente realista, surgiram os realistas neoclássicos, que são a terceira onda, e organizaram os avanços teóricos das duas ondas anteriores. ${ }^{5}$ Esse avanço teórico acumulado é utilizado para explicar um maior número de casos distribuídos por um espaço temporal maior ${ }^{6}$. Quanto ao tipo de análise elaborada, a maioria das pesquisas feitas por realistas neoclássicos, ao analisar como as grandes potências respondem a queda ou aumento do poder relativo, é qualitativa. Exemplos dessas análises vão desde os estudos de caso elaborados por Fareed Zakaria (1998) e Thomas J. Chirstensen (1998) sobre os Estados Unidos até o estudo de Willian Curti Wohlforth (1993) sobre a União Soviética.

Em relação à variável dependente, os realistas neoclássicos tentam explicar a variação do poder relativo de um Estado. No entanto, cada teórico dessa corrente define esse conceito de uma maneira diferente. Incluindo ou excluindo o que são as capacidades e recursos que devem ser analisados. Apesar de não haver uma única definição de interesse do

\footnotetext{
${ }^{4}$ Ao contrário de Friedberg que analisou o caso de declínio no poder relativo, Melvyn Leffler, outro teórico dessa segunda onda, estudou o caso dos Estados Unidos e sua ascensão no plano internacional. (LEFFLER, 1992).

${ }^{5}$ Para os realistas neoclássicos, o sistema anárquico internacional não é hobbesiano nem benigno, mas sim um cenário subjetivo, cabendo aos Estados fazerem a leitura e interpretação das circunstâncias, se de paz ou de escassez de recursos. Portanto, os realistas neoclássicos estão entre os teóricos estruturalistas, que acreditam que há uma ligação direta entre os limites sistêmicos e o comportamento dos Estados, e os construtivistas, que acreditam que o sistema anárquico é o que os Estados fazem dele, ou seja, é uma construção social.

${ }^{6}$ Como os trabalhos feitos por Fareed Zakaria (ZAKARIA, 1998), por exemplo.
} 
Estado nesta corrente, os teóricos concordam que todo Estado quer aumentar sua influência externa até o limite de sua capacidade.

Essa falta de clareza sobre poder relativo, está na incapacidade empírica de se testar o conceito "poder", já que a depender do período histórico, diferentes elementos que constituem o poder Estatal teriam pesos diferentes, como afirma Wohlforth:

\begin{abstract}
"Power cannot be tested; different elements of power possess different utilities at different times; the relation of perceived power to material resources can be capricious; the mechanics of power are surrounded by uncertainty; states possess different conversion ratios and comparative advantages; the perceived prestige hierarchy and the military distribution may not coincide for prolonged periods; states adopt asymmetrical strategies to maximize their positions and undercut rivals; signals get confused among allies, rivals, and domestic audiences 7
\end{abstract}

A hipótese central dos realistas neoclássicos é que os recursos materiais definem no longo prazo as ambições da política externa de cada Estado. Nesse sentido, a depender do aumento ou diminuição do poder relativo, os países iriam ajustar sua busca por influência externa conforme flutua seu poder relativo.

Para entender a variação do poder relativo, os teóricos dessa corrente procuram entender duas variáveis intervenientes. A primeira é como o poder do Estado é convertido em políticas eficazes que visam aumentar o próprio poder do Estado. A segunda variável interveniente para os realistas neoclássicos é a noção de poder estatal e como ela é aplicada nas relações internacionais. Assim sendo, há um componente doméstico e internacional na análise feita pelos realistas neoclássicos. Isso fica evidente na análise feita por Zakaria ao estudar o caso da ascensão estadunidense no Pós-Primeira Guerra Mundial, em que o autor tenta entender por que este país demorou para adotar uma postura mais ativa e expansionista. Zakaria ficou intrigado com o fato dos Estados Unidos perderem oportunidades de atuar de uma maneira mais agressiva, na tentativa de ampliar sua influência no mundo, apesar de ter se tornado uma das nações mais ricas no entreguerras. Após analisar diferentes oportunidades perdidas e contrapô-las com diversas teorias, o autor conclui que a política externa depende do meio que os políticos

\footnotetext{
${ }^{7}$ WOHLFORTH, William C. The Elusive Balance: Power and Perceptions During the Cold War. Cornell University Press, 1993, pp. 306-7.
} 
estão inseridos. O autor não nega a importância da capacidade nacional como variável explicativa das intenções de um Estado, mas adiciona à análise a variável poder estatal para explicar a relação entre capacidade material e comportamento dos decisores. (ZAKARIA, 1998). ${ }^{8}$

Ou seja, os teóricos realistas neoclássicos preferem uma análise que comece no plano internacional, mas que se atenha a detalhes micros como a capacidade nacional de transformar poder relativo em política externa efetiva. Essa preocupação metodológica aproxima os realistas neoclássicos dos idealistas, como por exemplo Robert O. Keohane (1986). Uma vez que o próprio Keohane advoca no sentido de que não haveria uma disputa entre um modelo parcimonioso e outro contextual, mas esses dois modelos representariam estágios. Dessa forma, os modelos parcimoniosos serviriam como guias e posteriormente se adicionariam variáveis específicas aumentando a complexidade do modelo, ao mesmo tempo em que se controla a sua capacidade preditiva. O ponto que distancia realistas neoclássicos e idealistas é justamente o peso que cada um deles aloca em um lado da balança: o modelo macro (parcimonioso) versus o modelo micro (detalhista). ${ }^{9}$

Dada a assimetria de poder e a falta de informação plena dos tomadores de decisão, os Estados aderem aos regimes internacionais de acordo com a posição do Estado dominante. Assim sendo, para os teóricos realistas as normas internacionais seriam o reflexo do interesse estatal do hegemon e a adesão a essas normas estaria sujeita à capacidade do Estado dominante em coagir/intimidar os outros Estados.

\footnotetext{
${ }^{8}$ A capacidade material de uma nação são todos os recursos dentro de um Estado. Por sua vez, o poder estatal é uma fração desse poder nacional, é a porção em que o governo pode utilizar, modificar e/ou remodelar conforme os tomadores de decisão bem entenderem). Dessa forma, Zakaria se aproxima da análise feita por Peter Evans, e sustenta a importância de um Estado forte, com uma burocracia eficiente que possa traduzir a capacidade nacional em política externa de uma maneira hábil e rápida. (EVANS, 1985).

${ }^{9}$ Outro ponto que distancia os realistas dos idealistas é a disponibilidade de informação que o tomador de decisão possui. Nesse tópico, Keohane (1986) comenta sobre o pressuposto racionalista utilizado pelos realistas para unir a estrutura sistêmica de poder internacional e o curso de ação do ator estatal. Assim sendo, os líderes políticos decidem de maneira racional com informação plena, ou seja, conseguem fazer uma leitura da distribuição de poder global e essa leitura é convertida em política externa. Portanto, para os teóricos sistêmicos, a leitura do plano internacional por líderes políticos é um processo bastante coerente e sem maiores obstáculos. Ao contrário, os realistas neoclássicos não concordam com essa premissa sistêmica e argumentam que os tomadores de decisão não têm informação plena do cenário internacional e por isso podem agir de maneira não racional. De modo que, a ligação entre capacidade e comportamento nacionais é irregular e caprichosa e muitas vezes não estratégicas, como um modelo estrutural prediria.
} 


\section{Liberalismo e fatores domésticos}

Em contraposição aos estudos realistas, os liberais focam sua análise mais nas características domésticas dos Estados. ${ }^{10}$ Essa corrente de pesquisa tem como raiz o ramo da teoria liberal que advoga pela promoção de bens públicos (exemplo: instituições políticas e identidade nacional) no plano doméstico. Nesse sentido, diferentemente do realismo e do idealismo, os liberais republicanos focam sua análise no plano doméstico. Portanto, a assinatura de um acordo ou tratado internacional (assim como de acordos domésticos) ocorre em decorrência de fatores domésticos e não tão internacionais. Um exemplo fornecido pelos teóricos dessa corrente se dá quando o governo de situação quer travar-locking-in-uma determinada política. Para tanto o governante adere a um tratado internacional, dificultando ou mesmo impossibilitando futuras administrações retrocederem na matéria.

Da mesma forma, o governo de situação cria órgãos independentes, como o banco central por exemplo, para insular uma política específica de disputas porvindouras. Segundo Moravcsik (MORAVCSIK, 2000, p. 227), um tomador de decisões racional deve contrabalançar dois elementos na hora de considerar delegar políticas a um corpo independente: (a) redução da incerteza política doméstica e (b) restringir a discrição do governo.

Quanto ao primeiro ponto, Moravcsik afirma que os governos democráticos internalizam normas de direitos humanos criadas por entidades internacionais afim de criar um mecanismo jurídico confiável para constranger futuros governos não democráticos ou governos eleitos democraticamente, que tentem alterar o regime político uma vez no poder. Essa medida serve como um mecanismo de comprometimento de dois níveis, "atando a mão" dos futuros governantes e aumentando a credibilidade das políticas e instituições do governo de situação (EVANS et al, 1993).

Quanto ao segundo ponto, reduzir a discrição do governo, pode ser interpretado como o custo de soberania no plano internacional, de acordo com Moravcsik. Seguindo a lógica proposta pelo autor, o governante é intrinsicamente cético quanto à possibilidade de delegar políticas aos órgãos independentes. Isso porque, não há nenhuma certeza que uma

\footnotetext{
${ }^{10}$ Corrente que faz parte das teorias de Innenpolitik (Rose, 1998). Innenpolitik (política doméstica em alemão), como o próprio nome indica, é a teoria que enfatiza a importância da política doméstica na formulação da política externa.
} 
vez delegada a política, as ações do órgão independente vão seguir os interesses políticos do governo - agency cost. Esse cenário que já é complicado no plano doméstico, se torna mais tortuoso no plano internacional, uma vez que o agency cost passa a ser um cálculo de custo de soberania. Tomando como exemplo os regimes internacionais de direitos humanos, o órgão independente transnacional ou internacional deve lidar com uma variação enorme da própria natureza, objetivo e aplicação de normas em cada país. Assim sendo, para um governante optar por delegar uma normativa para um órgão independente internacional muitas vezes não é uma escolha de preferência de primeira ordem.

A chave para a Moravcsik está no primeiro ponto - redução da incerteza política doméstica. Deste modo, para os liberais republicanos seriam as novas democracias, e não as democracias estabelecidas, os principais Estados interessados em ratificar tratados internacionais de direitos humanos. ${ }^{11} \mathrm{O}$ autor chega à essa conclusão ao analisar as negociações para a criação da Corte Europeia de Direitos Humanos (ECHR, em inglês). Todavia, o autor pontua que a teoria liberal republicana não explica sozinha a evolução dos regimes internacionais de direitos humanos. Dessa forma, há a necessidade de se encontrar outras variáveis que expliquem essa evolução:

\footnotetext{
Despite these important insights, however, the determinants of the evolution of human rights regimes are unlikely to be identical to the determinants of their founding and are therefore unlikely to be explained entirely by republican liberal theory. ${ }^{12}$
}

\section{Paz Democrática}

Para investigar os determinantes domésticos que influenciam no comportamento estatal no plano internacional surgiu a agenda de pesquisa da Democratic Peace (DP). Essa corrente teórica investiga se há uma diferença no plano internacional entre o comportamento das democracias em relação às autocracias. Fundamentalmente, a literatura da DP analisa se os regimes democráticos são mais pacíficos do que as autocracias. Essa corrente teórica tem como pressuposto que a interdependência econômica e as características do sistema político doméstico promovem a cooperação no

\footnotetext{
${ }^{11}$ Para os liberais republicanos, as democracias estabelecidas apoiariam outros países, principalmente as novas democracias, a ratificar tratados internacionais, visto que essa medida poderia trazer maior estabilidade (democratic peace) a uma região. Nessa situação, as democracias estabelecidas correm o risco de terem que ratificar o tratado, já que o estão promovendo, por isso Moravcsik argumenta que é maior a chance do interesse nacional das democracias estabelecidas prevalecer.

12 (MORAVCSIK, 2000, p. 246)
} 
plano internacional. Consequentemente, essa linha de raciocínio é derivada do pensamento Liberal, todavia preza por uma análise mais quantitativa para sustentar suas hipóteses, ao estabelecer uma correlação entre sistema político doméstico e comportamento internacional do país. Fazem parte dessa linha de pesquisa autores como: Bueno de Mesquita, Robert Putnam, George Tsebelis, Helen Milner e Robert Keohane, dentre outros.

A corrente Liberal teve forte ascensão no entreguerras, pois se acreditava que os Quatorze Pontos propostos pelo presidente estadunidense Woodrow Wilson fossem garantir a paz internacional, evitando assim novos conflitos motivados por ambições políticoeconômicas. As principais reivindicações do presidente Wilson eram que os Estados deveriam: (a) abolir a prática da diplomacia secreta; (b) eliminar as barreiras econômicas; e (c) criar a Liga das Nações. Essas medidas tinham o escopo de aumentar a interdependência econômica e criar canais de diálogo diplomático.

Todavia com o advento da Segunda Guerra Mundial as bases do liberalismo se viram fortemente abaladas. As potências ocidentais tentaram conter a expansão alemã por diversas vias diplomáticas. Um exemplo desse esforço foi o Acordo de Munique, em que a França e a Inglaterra concordaram em ceder o território do Sudetos, de maioria étnica alemã, da Checoslováquia para a Alemanha, a contragosto do governo tcheco. Depois, com a invasão alemã na Polônia, França e Inglaterra iniciaram um bloqueio naval para dirimir a capacidade de esforço de guerra alemã.

Essas medidas preliminares não foram suficientes para conter a expansão dos países do Eixo, e posteriormente foram vistas como responsáveis por permitir que a Alemanha ganhasse território e por prolongar a guerra por mais tempo. Como essas ações, que estavam amparadas na perspectiva idealista, ao priorizar o diálogo diplomático e a interdependência econômica, não foram capazes de solucionar o conflito, novas correntes teóricas (ou correntes teóricas existentes, mas com uma nova roupagem) surgiram no pósguerra.

O realismo começou a ganhar força neste período, justamente por colocar em xeque a prerrogativa idealista de cooperação internacional sustentada por uma instituição supranacional. Apesar da preponderância das teorias realistas no pós-guerra, os estudos liberais continuaram sendo desenvolvidos por teóricos concernidos com a capacidade das 
instituições internacionais, nominalmente a Organização das Nações Unidas (ONU), em solucionar potenciais conflitos (ONUKI, 2013).

\section{Adesão aos tratados internacionais de Direitos Humanos}

Feito o levantamento teórico das teorias que explicam o comportamento do Estado no plano internacional, optou-se pela teoria liberal republicana e sua vertente Paz Democrática para explicar a adesão a tratados internacionais de direitos humanos. Isso porque acreditamos que essa literatura abrange não só um maior número de variáveis, mas principalmente, por acreditarmos que a temática de direitos humanos é substancialmente diferente das outras temáticas. Essa diferença está no fato de que ao contrário de outras temáticas, direitos humanos envolve a preocupação com o ser humano, independentemente se ele está no interior das fronteiras do Estado ou não. Por isso, análises construídas para se entender a lógica da ascensão econômica ou militar de um Estado não são tão úteis para a nossa pesquisa.

Com a escolha teórica elaborada, a literatura sobre adesão aos tratados de direitos humanos possui duas vertentes explicativas das variáveis domésticas que levam à assinatura do regime internacional. A primeira corrente afirma que há uma correlação positiva entre o processo de democratização do país e o aumento na participação deste país em tratados e organizações internacionais de direitos humanos. Portanto, para estes autores, o regime político é uma variável relevante para se compreender o comportamento do Estado na arena internacional. Enquanto que a segunda vertente de estudos aponta para processo mais bottom-up, em que a participação de movimentos sociais e ONGs de direitos humanos é decisiva na alteração do comportamento estatal no campo internacional de direitos humanos. A lógica desse raciocínio está no efeito "do bumerangue espiral" (RISSE et al., 1999), que segundo estes autores parte da estratégia de mobilização da vergonha (shaming) feita pelas redes transnacionais de ativistas em direitos humanos com o intuito de apontar um Estado alvo como sendo um Estado nãocivilizado, já que este não segue as normas internacionais de direitos humanos. Esta pressão acaba por minar a credibilidade internacional do Estado alvo frente à comunidade internacional, bem como estremece a legitimidade doméstica do regime, fazendo com que este ceda e internalize algumas normas internacionais de direitos humanos. 
$\mathrm{Na}$ literatura da primeira vertente, o principal fator que envolve a transição democrática nas democracias recém-formadas é a incerteza política, gerando problemas de credibilidade e confiabilidade quanto ao novo regime. Esta incerteza é derivada em parte pela falta de histórico no compromisso com reformas democráticas, o que pode criar reformas políticas e institucionais incompletas que beneficiam os novos grupos que acenderam ao poder. Outra fonte de incerteza política, que não é exclusiva deste grupo de países, mas que devido à instabilidade política sofre um incremento, é a possibilidade de haver preferências temporalmente inconsistentes (MANSFIELD; PEVEHOUSE, 2006). E segundo estes autores, a questão da credibilidade é importante para as novas democracias, uma vez que:

\footnotetext{
"A inabilidade dos Estados em democratização de realizarem compromissos críveis pode gerar vários problemas. As elites frequentemente desconfiam umas das outras no período transicional e temem que o novo regime não sirva aos seus interesses. De forma mais ampla, se a população não acreditar que os esforços anunciados de reforma política são sinceros, é pouco provável que ela apoie o novo regime. Essa falta de apoio da sociedade pode ameaçar a consolidação democrática. Alguns grupos podem se opor de forma ativa ao regime, até mesmo recorrendo a medidas violentas ou se aliando com outros grupos descontentes na sociedade. A falta de apoio societal também pode levar o governo a tomar ações que desafiam a democracia (...) Em suma, como Whitehead argumenta, "se cada setor político concluir que o compromisso democrático do outro é pequeno isso reduzirá a motivação de todos, e assim perpetuar a condição de fragilidade". (MANSFIELD; PEVEHOUSE, 2006, p. 141).
}

Tendo este pano de fundo de incerteza política, os autores da primeira vertente divergem em duas correntes quanto às soluções encontradas pelas novas democracias para dirimir esse quadro. A primeira delas é a dos mecanismos de lock-in e a segunda, a necessidade de sinalizar tanto para o plano doméstico quanto para o internacional seu real compromisso com as reformas democráticas. Os mecanismos de lock-in, segundo Moravcsik (2000), servem para diminuir as incertezas políticas nas democracias recentes. Dessa forma, os atores governamentais se dispõem a delegar parte da autoridade para uma entidade internacional. Caso as normas desta entidade sejam descumpridas por grupos antidemocráticos no futuro gerará um custo político e um constrangimento internacional, “atando as mãos” dos líderes políticos e prevenindo a ocorrência de retrocessos da ordem democrática. A segunda corrente, que postula o mecanismo da sinalização 
(MANSFIELD, PEVEHOUSE 2006; 2008 e HAFNER-BURTON et al. 2008), afirma que além de servir como mecanismo de lock-in, a adesão às normas internacionais de direitos humanos visa sinalizar para a comunidade internacional e nacional o comprometimento dos atores governamentais com as reformas institucionais para a democracia.

A segunda vertente de autores, que partem de uma abordagem bottom-up, se concentram em avaliar o papel das redes transnacionais de ativistas de direitos humanos e seu impacto na adesão às normas internacionais pelo Estado-alvo. Já que somente a pressão de movimentos sociais e ONGs nacionais encontravam dificuldade em pressionar seus governantes para aderirem tratados internacionais de direitos humanos, acabavam por procurar aliados internacionais, principalmente movimentos sociais e ONGs de direitos humanos estabelecidos em países com democracia consolidada (SIKKINK, 1993; BRYSK, 1993; KECK; SIKKINK, 1998). A partir desta rede transnacional, estes atores usam a estratégia da vergonha (shaming) para abalar a imagem do Estado-alvo na comunidade internacional, criando uma pressão política suficiente para que os líderes governamentais acenem com algumas concessões, como internalizar normas internacionais de direitos humanos. O foco nas condicionantes domésticas destes estudos quantitativos tenta explicar o comportamento da política doméstica frente à pressão da opinião pública e da comunidade internacional em relação ao cumprimento de normas internacionais de direitos humanos (HATHAWAY, 2002; 2007; LANDMAN, 2005; CARDENAS; 2004; 2007; FRANKLIN, 2008; POWELL \& STATON, 2009; SIMMONS, 2009).

Diferentemente do modelo bumerangue de Keck e Sikkink de 1998 que sugeriu que o papel das redes transnacionais sobre os Estados violadores de direitos humanos era indireto, sendo mediado pela pressão da comunidade internacional e das organizações internacionais sobre o Estado-alvo, o trabalho de Franklin (2008) aponta para um papel mais direto destas redes ${ }^{13}$. Neste estudo Franklin analisa sete países da América Latina ${ }^{14}$ entre 1981 e 1995, e argumenta, através de uma análise quantitativa, que a estratégia da vergonha é eficaz em países com fortes laços econômicos com outros Estados, mas que a

\footnotetext{
${ }^{13}$ Segundo Franklin, a pressão das redes transnacionais de ONGs de direitos humanos, grupos religiosos e governos estrangeiros é mais eficaz do que a pressão de organizações internacionais.

${ }^{14}$ Os sete países analisados são: Argentina, Brasil, Chile, Guatemala, México, Nicarágua e Venezuela.
} 
duração desta capacidade de impacto é relativamente curta, sendo estimada em menos de seis meses pelo autor. Segundo Franklin:

\footnotetext{
"The overall amount of human rights criticism was found to have a strong positive relationship with the magnitude of political repression. This most likely reflects the fact that human rights criticism tends to target governments that have used repression in the past, which are then more likely to use repression in the future. However, human rights criticism tends to significantly decrease subsequent repression for countries that receive greater amounts of foreign aid and foreign investment. Thus, countries with greater ties to the outside world, and hence more to lose, tend to be more sensitive to their international human rights reputation. This finding holds up in the face of multiple controls for domestic factors and despite the fact that human rights criticism does not necessarily target the reactive repression studied here. This result suggests that human rights criticism will become more effective as the current trend in economic globalization continues". (FRANKLIN, 2008, p. 207).
}

Partindo de uma perspectiva mais institucional, mas também condicional, Neumayer (2005) afirma que o grau de democratização de um país influencia no resultado da adesão a um regime internacional de direitos humanos. De acordo com este autor, quanto mais a sociedade civil de um país participar de movimentos sociais e de ONGs de direitos humanos, mais efeitos benéficos serão produzidos pela internalização de uma norma de direitos humanos. No caso de países com baixo grau de democratização e sem uma sociedade civil ativa com vínculos internacionais a adesão não traz benefícios, muito pelo contrário, pode até se associar com um aumento das violações de direitos humanos. $\mathrm{O}$ autor conclui afirmando que:

\footnotetext{
"In most cases, for treaty ratification to work, there must be conditions for domestic groups, parties, and individuals and for civil society to persuade, convince, and perhaps pressure governments into translating the formal promise of better human rights protection into actual reality. Hafner-Burton and Tsutsui (2005) are right in suggesting a positive role of civil society strength on human rights, but it is the interaction with treaty ratification that often matters". Neumayer (2005)
} 


\section{Conclusões preliminares}

A análise sobre adesão a regimes internacionais tem embasamento teórico nas diferentes teorias de relações internacionais, desde o realismo ao idealismo, passando pelo construtivismo e a teoria crítica. Dessa forma, a depender da teoria empregada, a unidade de análise e os interesses dos agentes envolvidos na adesão aos tratados internacionais são distintos. Alterando todas as motivações e consequências que a adesão a um tratado internacional acarreta para o Estado. Tendo esse panorama em vista, esse artigo teve como objetivo examinar a origem e as características das principais correntes teóricas que versam sobre adesão a regimes, mais especificamente aos regimes internacionais de direitos humanos.

Os estudos com pressupostos do realismo argumentam que a adesão a um tratado internacional ocorre pela pressão de um Estado hegemônico. Dentre esses teóricos estão três correntes realistas de relações internacionais, a primeira onda de realistas buscava compreender a relação entre a ascensão e queda econômica de uma nação e sua respectiva importância militar no período. A segunda onda de realistas procurou entender como a mudança no poder relativo gera uma mudança na política externa. Diferenciando-os dos teóricos da primeira geração, uma vez que estes não se preocupavam com a possibilidade, muito menos com o processo, de perda ou ganho de poder no plano internacional. Por último, surgiram os realistas neoclássicos, que são a terceira onda, e organizaram os avanços teóricos das duas ondas anteriores. Esse avanço teórico acumulado é utilizado para explicar um maior número de casos distribuídos por um espaço temporal maior.

Em contraposição aos estudos realistas, as análises liberais sobre adesão aos regimes internacionais se desenvolveram com um foco nas características domésticas dos Estados. Essa corrente de pesquisa tem como raiz o ramo da teoria liberal que advoga pela promoção de bens públicos (exemplo: instituições políticas e identidade nacional) no plano doméstico. Portanto, a assinatura de um acordo ou tratado internacional ocorre por fatores doméstico e não tão internacionais. Um braço investigativo que surgiu a partir dos estudos liberais foi a agenda de pesquisa da Paz Democrática (Democratic Peace - DP). Tendo como objetivo investigar os determinantes domésticos que influenciam no comportamento estatal no plano internacional. Dentro desse arcabouço analítico, uma das perguntas mais intrigantes que os teóricos da Paz Democrática fazem é discutir se há 
diferença no plano internacional entre o comportamento das democracias em relação às autocracias. Apesar deste raciocínio ser derivado do pensamento Liberal, o avanço metodológico proposto pela DP é utilizar métodos quantitativos para sustentar suas hipóteses. Dessa forma, a intenção destes estudos é descobrir se há causalidade entre o sistema político doméstico de um Estado e seu comportamento internacional.

Com base nas teorias mencionadas previamente seria interessante examinar quais são os determinantes que influenciam a adesão aos regimes internacionais de direitos humanos. Assim seria possível estabelecer uma relação de associação entre as variáveis independentes e a adesão ao tratado - variável dependente. No próximo artigo tentaremos avançar com essa agenda de pesquisa. 


\author{
UNIVERSIDADE DE SÃO PAULO \\ INSTITUTO DE RELAÇÕES INTERNACIONAIS \\ PROGRAMA DE PÓS-GRADUAÇÃO EM RELAÇÕES \\ INTERNACIONAIS
}

MATHEUS SOLDI HARDT

\title{
OS DETERMINANTES QUE INFLUENCIAM NA ADESÃO AOS REGIMES INTERNACIONAIS DE DIREITOS HUMANOS: UMA ANÁLISE EMPÍRICA
}

São Paulo

2014 


\author{
UNIVERSIDADE DE SÃO PAULO \\ INSTITUTO DE RELAÇÕES INTERNACIONAIS \\ PROGRAMA DE PÓS-GRADUAÇÃO EM RELAÇÕES \\ INTERNACIONAIS
}

\title{
OS DETERMINANTES QUE INFLUENCIAM NA ADESÃO AOS REGIMES INTERNACIONAIS DE DIREITOS HUMANOS: UMA ANÁLISE EMPÍRICA
}

MATHEUS SOLDI HARDT

Dissertação apresentada ao Programa de
Pós-Graduação
Internacionais do

Orientador(a): Profa. Dra. Janina Onuki

São Paulo

2014 


\section{Resumo}

O estudo de adesão a regimes internacionais se desenvolveu na década de 1990 e a partir de então seu crescimento se deu majoritariamente no campo empírico, principalmente nos estudos sobre regimes de direitos humanos. Para além dessa constatação, quanto mais o campo de estudo de adesão aos regimes internacionais amadurece, mais os estudos tendem a analisar os aspectos domésticos que levaram à adesão de uma norma internacional e quais as implicações políticas de seguir ou não um determinado regime. Tendo em vista esse panorama geral, esta dissertação de mestrado pretende analisar quais as circunstâncias político-sociais que levam um país a aderir um regime de direitos humanos, no período de 1966 a 2012. Para tanto, analisamos cinco tratados internacionais: o Pacto Internacional dos Direitos Econômicos, Sociais e Culturais (1966), o Pacto Internacional de Direitos Civis e Políticos (1966), a Convenção sobre a Eliminação de Todas as Formas de Discriminação contra a Mulher (1979), a Convenção contra a tortura e outros tratamentos ou penas cruéis, desumanos ou degradantes (1984) e a Convenção do Direito das Crianças (1989). Os resultados indicam que a variável que mais impacta a adesão é o tipo de regime político do Estado. As democracias tendem a aderir mais aos regimes internacionais de direitos humanos do que as autocracias. $\mathrm{O}$ que reforça a teoria da Paz Democrática, que investiga se há uma diferença no plano internacional entre o comportamento das democracias em relação às autocracias.

Direitos Humanos, Regimes Internacionais, Regime Político, Paz Democrática 


\begin{abstract}
The studies of accession to international regimes developed in the 1990s and since then its growth was mainly in the empirical field, especially in studies on human rights regimes. In addition to this observation, the more the study of membership to international regimes field matures, the more the studies tend to analyze the domestic aspects that led to the membership of an international norm and to understand the political implications to comply or not with a particular regime. Given this overall picture, this dissertation aims at examining the political and social circumstances that lead a country to join a human rights regime, from 1966 to 2012. Therefore, five international treaties were analyzed: the International Covenant on Economic, Social and Cultural Rights (1966), the International Covenant on Civil and Political Rights (1966), the Convention on the Elimination of All Forms of Discrimination against Women (1979), the Convention against Torture and Other Cruel, Inhuman or Degrading Treatment or Punishment (1984) and the Convention of the Rights of Children (1989). The results indicate that the variable that most impacts the membership is the political regime of a state. Democracies tend to adhere more to international human rights regimes than autocracies. This reinforces the theory of Democratic Peace, which investigates whether there is a difference at the international level between the behavior of democracies in relation to autocracies.
\end{abstract}

Human rights, International regimes, Political regime, Democracy peace 


\section{Introdução}

Entender quais são as características que influenciam a adesão de um Estado à um tratado internacional é um desafio novo nas relações internacionais. Moravcsik (2000) relaciona os incentivos dos governos de participarem de regimes de direitos humanos a cálculos instrumentais na política doméstica. ${ }^{15}$ Nesse sentido, este artigo da dissertação de mestrado tem como objetivo analisar quais são as características que influenciam o Estado a aderir aos tratados internacionais de direitos humanos.

Um exemplo de situação que impulsiona os líderes políticos a aderir a estes tratados são períodos de transições políticas. Esses momentos são exemplos clássicos de situações que geram incertezas no que remete aos seus resultados. Para reduzir a incerteza política futura, os atores governamentais estão dispostos em situações como essas a adotar normas e novos comprometimentos internacionais, entre eles os relativos a direitos humanos. Em resposta à percepção de ameaça - de fato ou potencial - recorre-se ao âmbito internacional como um mecanismo de defesa frente ao possível opositor doméstico. Os novos compromissos assumidos internacionalmente blindam e protegem as mudanças feitas na política, ajudando a consolidar um projeto político interno, já que aumentam as dificuldades de que os opositores ou futuros sucessores possam modificá-lo.

No caso de regimes autoritários e repressivos, Risse et al. (1999), e também Keck e Sikkink (1998) oferecem a ideia do modelo bumerangue para se pensar a atuação do plano doméstico no comportamento estatal. Nesses casos, as estruturas internas são controladas por um Estado altamente centralizado que se apresenta como provedor das necessidades dos cidadãos, e que conta ainda com instituições e uma cultura política que concentram o poder no Executivo, o qual goza de grande independência do Legislativo. Segundo Keck e Sikkink (1998), frente então à repressão e falta de responsividade do Estado rompemse os vínculos entre o Estado e os atores internos, e põe-se em marcha o padrão bumerangue de influência, característico das redes transnacionais de ativismo: "em lugar de se dirigir a seu Estado, as ONGs nacionais buscam diretamente aliados internacionais

\footnotetext{
15 Segundo ele, "comprometimentos institucionais internacionais são, como os comprometimentos institucionais domésticos, mecanismos auto-interessados para o "trancamento" (locking-in) de certas políticas domésticas preferidas (...) em face da futura incerteza política” (MORAVCSIK, 2000, p. 226).
} 
para conseguir que se exerça pressão sobre este a partir do exterior" (Keck e Sikkink, 1998, p. 415).

Risse et al. (1999) argumentam, nesse sentido, que o estabelecimento de fortes e duradouros vínculos entre os grupos de oposição internos e as coalizões internacionais de ativismo e influência pode ter um efeito importante nos processos de abertura e democratização. As redes oferecem, dentre outros recursos, poder de negociação, informação e com frequência dinheiro aos grupos internos de oposição, cujas demandas muitas vezes conseguem ser amplificadas pela existência desses contatos internacionais. Isso porque, as ONGs internacionais que compõem a rede ao interpretarem as demandas locais apelam às normas internacionais para legitimar e reverberar as queixas e esforços dos ativistas domésticos.

Assim, Risse et al. (1999) argumentam que é mais factível que se produzam mudanças internas duradouras em matéria de direitos humanos quando os grupos de oposição e as ONGs internas formam redes com as ONGs internacionais que operam no âmbito transnacional,

\footnotetext{
"[A]s quais, por meio de estratégias de comunicação, conseguem mobilizar as instituições internacionais, a opinião pública ou os governos ocidentais para impugnar, pressionar ou persuadir os regimes que violam as normas para que aceitem a validade das mesmas, ao ratificar os acordos internacionais mais importantes, incorporar nas suas leis regras relativas aos direitos humanos e reconhecer tais normas em suas práticas discursivas.” (Risse et al., 1999, p. 389).
}

Todavia, para além das estruturas internas, que condicionam as formas de ação e estratégias das redes transnacionais e dos grupos políticos de oposição, há ainda de se lembrar do papel da institucionalização internacional das normas concernentes aos direitos humanos. Risse et al. afirmam que quanto mais as relações interestatais forem reguladas por instituições internacionais, mais intensas serão as atividades transnacionais e menor será a capacidade do governo para restringi-las. Em outras palavras, as instituições internacionais e as normas que elas carregam consigo facilitam o acesso dos atores transnacionais aos processos de formulação das políticas internas (Risse et al., p. $395)$. 
As normas internacionais "empoderam" e legitimam as redes e coalizões transnacionais que as promovem (Khagram et al., 2002, p. 16) porque atores não estatais que de outra forma seriam fracos podem explorar a legitimidade inerente às normas internacionais para construir redes transnacionais e transformar concepções até então prevalecentes. Risse et al. afirmam, nesse sentido, que "[o]s regimes e organismos internacionais aumentam o número de canais aos quais os atores transnacionais podem recorrer para influenciar as políticas dos governos. As instituições internacionais facilitam o lobby que realizam as redes transgovernamentais e as ONGs internacionais" (Risse et al., pp. 395-396).

Cabe observar aqui que o cumprimento dos regimes internacionais de direitos humanos é observado de maneira constante pelas ONGs internacionais, que tornam públicas as violações cometidas pelos governos e fortalecem os atores internos defensores dessas normas. O que faz então o modelo bumerangue é demonstrar justamente como as normas internacionais de direitos humanos fortalecem os grupos e organizações transnacionais e domésticos, em oposição aos Estados violadores de suas disposições. As normas dão poder a esses grupos, e legitimam suas reivindicações, aumentando sua influência potencial sobre as práticas estatais.

No entanto, para Vreeland (2008) o modelo bumerangue e qualquer outro modelo, que tente explicar a capacidade de mudança de um regime político, deve levar em consideração a existência ou não de grupos políticos opositores com certa capacidade de influência no regime. A motivação que levou Vreeland a escrever o artigo foi o texto de Neumayer (2005), em que este autor afirma que há diferença qualitativa entre as democracias e as ditaduras que assinaram a Convenção contra a prática de tortura. Mais especificamente, após entrarem para essa Convenção as democracias apresentaram uma diminuição nos casos de tortura, enquanto que as ditaduras apresentaram piora nos casos de violação aos direitos humanos.

A partir dos resultados deste paper, Vreeland conclui que há a necessidade de uma avaliação mais cuidadosa sobre as motivações que os regimes ditatoriais têm para entrar na Convenção contra a prática de tortura. É essa pergunta que Vreeland tenta responder no seu artigo de 2008, que aponta a existência de ruptura dentro dos regimes autoritários como fator motivador dos ditadores para aderir a esta Convenção. Os achados de Vreeland enfatizam a importância das instituições políticas domésticas para entender o comportamento dos Estados no plano internacional. 
Esta dissertação pretende analisar quais são as características dos Estados associadas à adesão aos tratados internacionais de direitos humanos. Para tanto, a estrutura deste artigo é a seguinte, primeiro apresentaremos a hipótese da pesquisa. Depois descreveremos os tratados internacionais de direitos humanos que iremos examinar; em terceiro lugar apresentaremos a metodologia de pesquisa. Subsequentemente, faremos uma breve avaliação sobre a velocidade de adesão aos diferentes tratados internacionais analisados. Em seguida, exporemos os resultados da regressão xtlogit bem como a análise destes. Por fim, apresentamos a conclusão e a agenda de pesquisa futura.

\section{Hipótese}

Como debatido, há diferentes campos nos estudos das determinantes da adesão aos tratados internacionais de direitos humanos, que estão descolados. Essa dissertação de mestrado pretende analisar em quais circunstâncias, entre 1966 e 2012, um Estado está mais propenso a internalizar normas internacionais de direitos humanos, seja pela iniciativa dos líderes governamentais ou pela pressão de opositores políticos ou movimentos sociais. Utilizando uma abordagem quantitativa tentaremos apontar quais características dos Estados estão associadas à adesão aos tratados de direitos humanos. A hipótese nula $\left(h_{0}\right)$ da pesquisa é de que a adesão às normas internacionais de direitos humanos não possui nenhuma condicionante doméstica para ocorrer. Tanto democracias como autocracias internalizam estas normas independentemente do tipo de regime político que o Estado possui. Essa hipótese tem embasamento teórico na corrente realista das Relações Internacionais, que afirma que o comportamento estatal tem explicações no jogo de poder do plano internacional.

ho: As características domésticas do Estado não influenciam na adesão aos regimes internacionais.

A hipótese alternativa $\left(h_{1}\right)$ afirma que a adesão aos tratados internacionais de direitos humanos tem fortes condicionantes nas características domésticas do Estado. O estudo da hipótese alternativa $\left(h_{1}\right)$ tem duas estratégias: a primeira enfatiza o papel das elites políticas, a segunda dos movimentos políticos opositores e do nível de violações dos 
direitos humanos. ${ }^{16}$ A primeira estratégia afirma que as elites políticas internalizam essas normas para diminuir a incerteza política tanto doméstica quanto internacional. A segunda estratégia enfatiza o papel dos grupos políticos opositores e dos movimentos sociais como fundamental para a adesão de tratados internacionais de direitos humanos.

\section{$h_{1}:$ : As características domésticas do Estado influenciam na adesão aos regimes internacionais.}

\section{Tratados internacionais de direitos humanos}

As atrocidades cometidas na Segunda Guerra Mundial criaram um consenso nos líderes mundiais de que os direitos do Homem deveriam ser assegurados por mecanismos internacionais. Isso porque, as minorias nacionais poderiam e foram perseguidas por políticas nacionais. Dentro desse panorama, diferentes regimes internacionais de direitos humanos surgiram no plano internacional. Esta dissertação de mestrado pretende analisar seis dos principais instrumentos normativos internacionais de direitos humanos que estão sob a tutela das Nações Unidas (ONU).

Tabela 1: Tratados internacionais de direitos humanos analisados:

\begin{tabular}{|c|l|c|}
\hline Sigla & \multicolumn{1}{|c|}{ Nome do tratado } & $\begin{array}{c}\text { Ano de } \\
\text { criação* }\end{array}$ \\
\hline ECOSOC & $\begin{array}{l}\text { Pacto Internacional dos Direitos Econômicos, } \\
\text { Sociais e Culturais }\end{array}$ & 1966 \\
\hline CIVPOL & $\begin{array}{l}\text { Pacto Internacional de Direitos Civis e } \\
\text { Políticos }\end{array}$ & 1966 \\
\hline CEDAW & $\begin{array}{l}\text { Convenção sobre a Eliminação de Todas as } \\
\text { Formas de Discriminação contra a Mulher }\end{array}$ & 1979 \\
\hline TORTURA & $\begin{array}{l}\text { Convenção contra a tortura e outros } \\
\text { tratamentos ou penas cruéis, desumanos ou } \\
\text { degradantes }\end{array}$ & 1984 \\
\hline CRIAN & Convenção do Direito das Crianças & 1984 \\
\hline
\end{tabular}

* Em ordem cronológica

Um exemplo destes tratados é o Pacto Internacional dos Direitos Econômicos, Sociais e Culturais (PIDESC) adotado pela Assembleia das Nações Unidas no final de 1966. Esse

\footnotetext{
${ }^{16}$ Para maiores informações sobre como mensurar violações de direitos humanos ver: LANDMAN \& CARVALHO, 2010.
} 
tratado é um dos tratados fundadores da ONU, juntamente com o Pacto Internacional de Direitos Civis e Políticos (PIDCP) e a Declaração Universal do Direito dos Homens. Com o fim da Segunda Guerra Mundial e o começo da polarização entre os EUA e a União Soviética (Guerra Fria), o interesse dos líderes mundiais era evitar uma nova guerra entre as principais nações e proteger as minorias étnicas. Uma das preocupações naquele período era limitar a capacidade de expansão territorial e preservar a autonomia dos Estados menos desenvolvidos, criando assim zonas satélites às duas superpotências. Tendo esse contex to em vista, tanto o PIDESC como o PIDCP reforçam, logo na primeira parte do texto, o direito à autodeterminação dos povos e dos seus territórios, garantido a liberdade de escolha do regime político e assegurando o livre "desenvolvimento econômico, social e cultural" dos Estados membros tanto do PIDESC como do PIDCP.

O Pacto Internacional de Direitos Civis e Políticos (PIDCP) de 1966 reune todos os direitos humanos "tradicionais", que foram reconhecidos previamente pelas Constituição dos Estados Unidos de 1798 e pela Declaração dos direitos do Homem e do Cidadão (Déclaration des droits de l'homme et du citoyen) do mesmo ano. Entre os direitos reconhecidos pelo PIDCP está o princípio da não discriminação e o direito à vida. $\mathrm{O}$ impacto deste regime se deu na elaboração de inúmeras constituições nacionais que foram escritas posteriormente ao Pacto.

A separação entre os direitos econômicos, sociais e culturais dos direitos civis e políticos foi reflexo do embate entre os EUA e a União Soviética. O primeiro acreditava que os direitos econômicos, sociais e culturais são direitos que devem ser almejados, mas não assegurados formalmente. Enquanto que os direitos civis e políticos deveriam ser respeitados sem restrições por todos os Estados. Por sua vez, a União Soviética argumentava justamente o contrário. A solução encontrada foi separar essas duas dimensões dos direitos humanos em dois corpos normativos, assim cada Estado julgaria a necessidade de aderir à eles. No final, apesar da relutância das duas superpotências na necessidade da implementação destes tratados internacionais, os países do Terceiro Mundo os pressionaram para que aprovassem os resultados das comissões que prepararam os textos do PIDESC e do PIDCP.

Outro regime internacional de direitos humanos que analisaremos é a Convenção sobre a Eliminação de Todas as Formas de Discriminação contra a Mulher (CEDAW, em inglês) de 1979. Até então não havia um documento que agrupasse em um único texto os direitos 
políticos, econômicos, sociais, culturais e sociais das mulheres. Além de não haver um texto único, havia a preocupação de que os regimes existentes, o PIDESC e o PIDCP, não estavam funcionando como deveriam para promover e proteger os direitos das mulheres. Assim a Assembleia Geral da ONU pediu para que a Comissão sobre o Status da Mulher da ONU elaborasse um documento unificado que articulasse os direitos de igualdade entre homem e mulher. Sendo o resultado acumulado de mais de 30 anos de trabalho da Comissão sobre o Status da Mulher a CEDAW foi adotada pela Assembleia da ONU em 1979.

O quarto regime internacional que analisaremos é a Convenção contra a tortura e outros tratamentos ou penas cruéis, desumanos ou degradantes de 1984. Esta Convenção também foi criada devido à descrença com os mecanismos domésticos de controle da tortura. Isso porque na década de 1970, o Brasil, a Argentina e a África do Sul utilizavam a tortura como política de Estado para reprimir opositores políticos. Os relatórios feitos pela Anistia Internacional, neste período, relatando as atrocidades cometidas nestes três países, entre outros 95 países, pressionaram a ONU a adotar a Declaração contra a Tortura. (LIPPMAN, 1994, p. 307).

Apesar da Declaração ter sido o primeiro instrumento normativo a condenar a prática de tortura no âmbito internacional, ela falhava ao não reconhecer a tortura como mecanismo de controle político. A Anistia Internacional percebeu que a Declaração não era um regime eficaz e começou a argumentar pela necessidade de uma Convenção que reconhecesse as novas práticas de tortura bem como outras formas de tratamento desumanos que estavam sendo praticados por agentes estatais. Em 1984, a Assembleia Geral da ONU adotou a Convenção contra a tortura e outros tratamentos ou penas cruéis, desumanos ou degradantes.

O último tratado que será analisado por esta dissertação é a Convenção do Direito das Crianças de 1989. Assim como os regimes supracitados, esta Convenção teve como contexto as contradições do século XX. Isso porque, devido as reformas e melhorias na condição material das famílias no século XIX, houve uma mudança na mentalidade das pessoas sobre o que significava uma infância saudável e a necessidade de investimento na formação e desenvolvimento das crianças (FASS, 2011). Porém com o advento das duas Guerras Mundiais essa quimera foi abalada, expondo a vulnerabilidade do direito das crianças. 
A Convenção do Direito das Crianças teve como base a Declaração do Direito das Crianças. Como esta última não era um instrumento normativo que gerasse vínculo legal aos Estados, em 1978 a Polônia submeteu a Comissão de Direitos Humanos da ONU um primeiro rascunho do que viria a ser a Convenção. Em 1989, depois de 11 anos de trabalho a Comissão de Direitos Humanos aprovou e transmitiu o texto para apreciação da Assembleia Geral da ONU que adotou a Convenção no final deste mesmo ano.

No entanto, o texto da Convenção do Direito das Crianças não deixou claro a proibição do recrutamento de crianças nas Forças Armadas. O artigo 38 da Convenção apenas afirma que os Estados-membros deverão tomar todas as medidas factíveis para limitar o alistamento de pessoas menores de 15 anos. Essa brecha legal aliada com as fotos de crianças armadas nos conflitos subsaarianos na década de 1990 pressionaram as Nações Unidas a adotar um Protocolo Adicional à Convenção. O Protocolo Adicional sobre o Envolvimento de Crianças em Conflitos Armados foi adotado pela Assembleia Geral em 2000 e proíbe definitivamente o emprego de crianças, pessoas menores de 18 anos, nas Forças Armadas. Lembrando que as crianças não possuem nem a força física nem a maturidade mental para entenderem a seriedade de um conflito armado.

Serão esses os cinco tratados internacionais que analisaremos nesta dissertação de mestrado. Eles foram escolhidos porque englobam diferentes dimensões dos direitos humanos, desde os direitos civis e políticos, passando pelos direitos econômicos e sociais e contra a tortura, bem como o direito de minorias históricas, como as mulheres e as crianças. Outro fato que determinou a escolha destes tratados é que todos os cinco pertencem ao guarda-chuva normativo da ONU. Esse dado é importante, uma vez que para uma análise quantitativa da adesão precisamos de tratados que possuam a capacidade de atrair o maior número de Estados-membros ou o contrário, de repelir o maior número de Estados. Assim, faz todo o sentido analisarmos tratados de direitos humanos adotados pela Assembleia Geral da ONU, um dos órgãos internacionais com maior número de Estado-membros. 


\section{Metodologia}

Como discutido anteriormente, analisaremos as características do Estado que impactam na adesão aos regimes internacionais. Para tanto, rodaremos uma regressão xtlogit. Esse método foi escolhido uma vez que a variável dependente - aderiu ao tratado ou não - é dicotômica, assumindo o valor 0 (zero) nos anos em que o país não aderiu ao tratado e o valor 1 (um) nos anos em que o país assinou o tratado internacional de direitos humanos ${ }^{17}$. Para além desse fato, o tempo é uma variável que influencia na nossa análise. Nesse sentido, precisávamos escolher um modelo que suportasse variáveis dependentes binárias em uma série temporal. O período a ser analisado é, consequentemente, entre 1966 e 2012, assim poderemos examinar todo o intervalo temporal dos seis tratados.

Com o período de análise e os tratados internacionais determinados, as variáveis independentes que serão examinadas para verificar sob quais circunstancias os Estados aderem a regimes de direitos humanos estão baseadas na literatura de adesão aos tratados internacionais e são as seguintes: ${ }^{18}$

1. EMIL: Variável binária que identifica se o governante efetivo é ou já foi um militar profissional. Espera-se que essa variável tenha sinal negativo na regressão, isso indicaria que os governantes não militares aderem mais aos tratados internacionais de direitos humanos.

2. DEMOCRACY: Variável binária que identifica a natureza do regime político do país. Esta variável foi retirada do banco de dados Democracy and Dictatorship construída por José Antonio Cheibub et al. Acreditamos que essa seja a variável fundamental do modelo, pois cremos que a relação será positiva e que tenha o maior impacto no modelo. Caso isso ocorra, dará maior fundamento empírico a teoria da Paz Democrática.

\footnotetext{
17 Os cinco regimes de direitos humanos que serão analisados: o Pacto Internacional dos Direitos Econômicos, Sociais e Culturais de 1966, o Pacto Internacional de Direitos Civis e Políticos de 1966, a Convenção sobre a Eliminação de Todas as Formas de Discriminação contra a Mulher (CEDAW) de 1979, a Convenção contra a tortura e outros tratamentos ou penas cruéis, desumanos ou degradantes de 1984 e a Convenção do Direito das Crianças de 1989.

${ }^{18}$ Para maiores informações sobre as variáveis independentes consultar o Apêndice I - Codebook, e o Apêndice II - Sumário do Banco de Dados.
} 
3. AGEDEM: Variável contínua que calcula a idade em anos do presente regime político classificado como Democracia. Essa variável tem como objetivo identificar o comportamento das democracias consolidadas. Esperamos encontrar uma relação positiva, mas de magnitude pequena.

4. ALLHOUSE: Variável binária que classifica se o partido político tem maioria absoluta nas esferas que tem capacidade de criar leis (houses that have lawmaking powers). Essa variável indicará se os achados de Vreeland (2008) para a Convenção contra a tortura podem ser expandidos para outros tratados internacionais de direitos humanos. ${ }^{19}$ Cremos que a variável terá uma relação negativa com as variáveis dependentes.

5. CIRI_PHYSINT: O índice dos direitos da integridade física (CIRI - Physical Integrity Rights Index) é uma variável categórica ordinal. Esta variável é construída a partir da soma de outras quatro variáveis que variam de 0 a 2 e avaliam: tortura (CIRI_TORT), mortes extrajudiciais (CIRI_KILL), detenção de políticos (CIRI_POLPRIS) e desaparecimentos (CIRI_DISAP). Portanto esse índice pode variar e de 0 (o governo não respeita nenhum desses quatro direitos) até 8 (o governo respeita esses quatro direitos). Quanto aos resultados, acreditamos que a relação será negativa, já que os Estados que não apresentam violações de direitos humanos não possuem incentivos políticos nem sociais para aderirem aos tratados. Nesses casos, a legislação doméstica muito possivelmente já resguarda esses direitos com eficácia. Os Estados em que as violações de direitos humanos ocorrem possuem um maior incentivo ou sofrem uma maior pressão para que assinem os tratados, já que a legislação doméstica não é suficiente para proteger esses direitos.

6. SYSTEM_D: Variável categórica que indica a natureza do sistema político do país. Por fim, entre as variáveis independentes, aguardamos que essa variável apresente uma relação negativa, indicando a tendência de aderir aos tratados em favor dos sistemas presidencialista. Esse resultado indicaria que quando o líder do executivo tem autonomia para aderir aos tratados, ele adere mais prontamente.

\footnotetext{
${ }^{19}$ Vreeland deixa essa questão em aberto na conclusão do seu paper (VREELAND, 2008, p. 94).
} 
Variável controle

1. LOG_UNNA_GDP: Logaritmo de uma variável contínua que mede o PIB (produto interno bruto) do país a preço constante de 2005 em dólares estadunidenses. Por último, acreditamos que essa variável terá uma relação estatisticamente significativa e positiva. $\mathrm{O}$ que em outras palavras indica que os Estados mais ricos aderem mais aos tratados internacionais de direitos humanos analisados.

A partir de todos estes dados, foi construído um banco de dados para realizar os testes de hipóteses, que foram discutidos no subitem Hipótese. ${ }^{20}$ Para a hipótese nula $\left(h_{0}\right)$ ser verdadeira espera-se que as variáveis domésticas como emil, democracy e system_d não sejam estatisticamente significativas. Esse fato demonstraria que a adesão aos tratados tem como característica preponderante o fator internacional. Ou seja, quando Estados vizinhos assinam o tratado acabam por criar uma situação favorável para que o Estado em questão assine também. Essa lógica foi descrita por Sikkink (2011) como efeito contágio que ocorreu na América Latina, entre as décadas de 1980 e 2000.

A hipótese alternativa $\left(h_{1}\right)$ será testada por duas estratégias. A primeira analisará se novas democracias, observadas através da variável agedem, aderem mais do que as democracias consolidadas e as autocracias. Já que significaria que a recente elite política adere a estes tratados para garantir as reformas democráticas e "atar as mãos" de futuros grupos antidemocráticos que acedam ao poder no futuro. Ao se confirmar a hipótese alternativa $\left(h_{1}\right)$, saberemos sob quais condições e em que período as afirmações desta vertente de estudos são válidas (MORAVCSIK, 2000; MANSFIELD; PEVEHOUSE, 2006; 2008; HAFNER-BURTON et al, 2008).

A segunda estratégia para testar a hipótese alternativa $\left(h_{1}\right)$, será a relação entre o tipo de regime político, democracias e autocracias, e a existência de grupos políticos opositores. Isto validaria a discussão feita pelo grupo de autores que parte de uma abordagem bottomup, ao afirmar que a estratégia da vergonha (shaming) feita pelos grupos de ativistas em direitos humanos e suas redes transnacionais acaba por pressionar os líderes

\footnotetext{
${ }^{20}$ Ver diferença entre n-grande, n-pequeno e estudo de caso em pesquisas sobre direitos humanos -
} LANDMAN, 2002 
governamentais a internalizarem normas internacionais de direitos humanos (BRYSK, 1993; KECK; SIKKINK, 1998; RISSE et al., 1999; WIIK, 2002; CARDENAS, 2004; 2008; NEUMAYER, 2005; FRANKLIN, 2008; SIMMONS, 2009).

\section{Velocidade de adesão aos regimes de direitos humanos}

Um primeiro exercício foi averiguar a velocidade de adesão aos tratados de direitos humanos analisados. A tabela 2 abaixo mostra os dados para a média de velocidade de adesão para cada um dos seis tratados analisados. A média foi calculada para cada tratado, sendo que ela é o tempo em média levado pelos países para assinarem o tratado, dividido pelo valor TER (tempo de existência do regime). Dessa forma sabemos que o tratado ECOSOC teve média de velocidade de adesão em $43 \%$ do seu tempo de criação até o ano de 2012.

Tabela 2: Velocidade de adesão dos tratados

\begin{tabular}{|c|c|c|c|c|c|}
\hline & $\begin{array}{l}\text { Ano de } \\
\text { criação }\end{array}$ & TER* & $\begin{array}{c}\text { Número de } \\
\text { países }\end{array}$ & $\begin{array}{l}\text { Média de } \\
\text { velocidade }\end{array}$ & $\begin{array}{l}\text { Desvio } \\
\text { Padrão }\end{array}$ \\
\hline ECOSOC & 1966 & 46 & 191 & 0,43 & 0,24 \\
\hline CIVPOL & 1966 & 46 & 191 & 0,45 & 0,24 \\
\hline CEDAW & 1979 & 33 & 191 & 0,31 & 0,23 \\
\hline TORTURA & 1984 & 28 & 191 & 0,38 & 0,25 \\
\hline CRIAN & 1989 & 23 & 191 & 0,13 & 0,09 \\
\hline Total (média) & & 35,20 & 191 & 0,34 & 0,21 \\
\hline
\end{tabular}

* Tempo de existência do regime (em anos, contados até 2012) ${ }^{21}$

Todos os tratados tiveram uma média de velocidade de adesão bastante similar. O único tratado que apresenta uma média de velocidade bastante inferior é o da Convenção do

\footnotetext{
${ }^{21}$ Em sua tese de livre docência, Janina Onuki elaborou uma tabela de velocidade de ratificação para 13 regimes internacionais de segurança (ONUKI, 2013).
} 
Direito das Crianças de 1989. Em apenas 13\% do tempo de existência deste tratado os países já haviam aderido a ele.

Por fim, os resultados do desvio padrão também indicam que a dispersão dos dados da média de velocidade é parecida para todos os tratados, com exceção novamente da Convenção do Direito das Crianças. A ressalva que pode ser feita a CRIAN foi a divulgação de imagens que percorreram o mundo na década de 1990 de crianças carregando metralhadoras AK-47 em conflitos na região subsaariana como Ruanda, Libéria e Serra Leoa. Essas imagens chocaram a comunidade internacional e pressionaram os Estados a adotar a Convenção Internacional o mais rápido possível. Por fim, as duas superpotências até aquele momento, os EUA e a União Soviética, não se opuseram à Convenção, gerando maior incentivo para a sua adoção.

\section{Análise das regressões $x$ tlogit}

Como podemos observar na tabela 3, os resultados das regressões xtlogit corroboram com a teoria e refutam a hipótese nula $\left(h_{0}\right)$, já que as variáveis domésticas são estatisticamente significativas, como é o caso da emil e da democracy. Em relação à variável emil (se o chefe de Estado efetivo é um membro das forças armadas), os resultados apoiam as previsões feitas pela teoria, de que regimes militares possuem uma tendência de não adesão aos tratados de direitos humanos, isso se compararmos com o comportamento dos Estados dirigidos por civis. O coeficiente é negativo e estatisticamente significante para todos os cinco tratados.

A variável DEMOCRACY, que indica se o país é ou não é uma democracia, é estatisticamente significante para os cinco tratados e o seu sinal positivo indica que as democracias aderem mais aos regimes internacionais de direitos humanos. O resultado dessa variável é curioso, já que sustenta empiricamente as proposições teóricas feitas pela teoria da Paz Democrática.

A variável AGEDEM é estatisticamente significativa para todos os tratados e possui o sinal positivo. Isso indica que se o Estado é uma democracia consolidada, essa característica tem um efeito positivo na adesão aos tratados de direitos humanos. Mostrando que a propriedade que importa em termos temporais é se o Estado é uma democracia consolidada e não nova democracia. 
Os resultados para ALLHOUSE foram apenas estatisticamente significativos para dois casos, TORTURA e CRIAN. Para os dois tratados o coeficiente foi negativo, o que significa que o partido político da situação não detinha maioria absoluta no Legislativo ao aderir aos tratados internacionais. Esse efeito pode ser interpretado segundo a lógica do mecanismo de lock-in, proposto por Moravcsik (2000) e Landman (2005), que serve para diminuir as incertezas políticas nas democracias recentes, uma vez que o governo de situação não possui maioria no Legislativo, é necessário delegar parte da autoridade para uma entidade internacional. Assim, caso as normas desta entidade internacional sejam descumpridas por grupos antidemocráticos no futuro gerará um custo político e um constrangimento internacional, "atando as mãos" dos líderes políticos e prevenindo a ocorrência de retrocessos da ordem democrática. Esse resultado também foi encontrado por Vreeland (2008), que ao analisar o comportamento das ditaduras, encontrou que na existência de grupos opositores dentro dos regimes autoritários, acaba por forçar estes regimes a aderir à Convenção contra a tortura. Essa medida serve para apaziguar esses grupos opositores.

Quanto aos resultados da variável independente CIRI_PHYSINT, eles são compatíveis com o que a literatura prevê, já que o coeficiente é negativo e estatisticamente significativo para todos os tratados. Esse resultado era esperado, pois os Estados que aderem aos tratados de direitos humanos tendem a alterar uma realidade doméstica através de instrumentos internacionais como um mecanismo de sinalização como postularam MANSFIELD \& PEVEHOUSE 2006; 2008 e HAFNER-BURTON et al. 2008. Assim sendo, países classificados com 8 (países respeita os quatro direitos humanos analisados) tendem a não ratificar os tratados internacionais de direitos humanos, isso porque a realidade doméstica já resguarda os direitos humanos dos seus cidadãos.

Os resultados da última variável independente, SYSTEM_D, foram positivos e estatisticamente significativos para todos os cinco modelos. Isso indica que as democracias que aderiram aos tratados eram sistemas presidencialistas. Por sua vez, a variável controle do modelo, LOG_UNNA_GDP, apresentou resultados estatisticamente significativos e positivos para todos os tratados. Portanto, os Estados com um maior produto interno bruto (PIB) tendem a aderir mais aos tratados internacionais de direitos humanos. 
Tabela 3: Teste $x$ tlogit para todos os tratados

\begin{tabular}{|c|c|c|c|c|c|}
\hline VARIABLES & $\begin{array}{c}(1) \\
\text { ECOSOC }\end{array}$ & $\begin{array}{c}(2) \\
\text { CIVPOL }\end{array}$ & $\begin{array}{c}\text { (3) } \\
\text { CEDAW }\end{array}$ & $\begin{array}{c}(4) \\
\text { TORTURA }\end{array}$ & $\begin{array}{c}(5) \\
\text { CRIAN }\end{array}$ \\
\hline emil & $\begin{array}{c}-3.785 * * * \\
(0.755)\end{array}$ & $\begin{array}{c}-3.028 * * * \\
(0.708)\end{array}$ & $\begin{array}{c}-1.593 * * * \\
(0.489)\end{array}$ & $\begin{array}{c}-1.897 * * * \\
(0.491)\end{array}$ & $\begin{array}{c}-2.495 * * * \\
(0.420)\end{array}$ \\
\hline democracy & $\begin{array}{c}6.454 * * * \\
(1.092)\end{array}$ & $\begin{array}{c}10.63^{* * *} * \\
(1.295)\end{array}$ & $\begin{array}{c}4.511 * * * \\
(0.702)\end{array}$ & $\begin{array}{c}3.938 * * * \\
(0.574)\end{array}$ & $\begin{array}{c}5.174 * * * \\
(0.554)\end{array}$ \\
\hline agedem & $\begin{array}{c}0.0149 \\
(0.0158)\end{array}$ & $\begin{array}{c}0.0604 * * * \\
(0.0145)\end{array}$ & $\begin{array}{c}0.108 * * * \\
(0.0143)\end{array}$ & $\begin{array}{l}0.0251 * \\
(0.0130)\end{array}$ & $\begin{array}{c}0.0669 * * * \\
(0.0101)\end{array}$ \\
\hline allhouse & $\begin{array}{l}-0.967 \\
(0.653)\end{array}$ & $\begin{array}{l}-0.691 \\
(0.585)\end{array}$ & $\begin{array}{l}-0.690 \\
(0.520)\end{array}$ & $\begin{array}{c}-1.236 * * * \\
(0.366)\end{array}$ & $\begin{array}{c}-0.929 * * * \\
(0.350)\end{array}$ \\
\hline 1.ciri_physint & $\begin{array}{l}1.627 * \\
(0.840)\end{array}$ & $\begin{array}{l}-0.400 \\
(0.779)\end{array}$ & $\begin{array}{l}0.0323 \\
(0.734)\end{array}$ & $\begin{array}{c}0.950 \\
(0.622)\end{array}$ & $\begin{array}{c}0.454 \\
(0.474)\end{array}$ \\
\hline 2.ciri_physint & $\begin{array}{l}1.635 * * \\
(0.808)\end{array}$ & $\begin{array}{l}-0.302 \\
(0.732)\end{array}$ & $\begin{array}{l}-0.0779 \\
(0.646)\end{array}$ & $\begin{array}{l}1.090^{*} \\
(0.619)\end{array}$ & $\begin{array}{c}0.697 \\
(0.435)\end{array}$ \\
\hline 3.ciri_physint & $\begin{array}{c}0.991 \\
(0.767)\end{array}$ & $\begin{array}{l}-0.686 \\
(0.679)\end{array}$ & $\begin{array}{l}-0.0607 \\
(0.685)\end{array}$ & $\begin{array}{c}0.963 \\
(0.600)\end{array}$ & $\begin{array}{c}0.572 \\
(0.435)\end{array}$ \\
\hline 4.ciri_physint & $\begin{array}{l}-0.0816 \\
(0.738)\end{array}$ & $\begin{array}{c}-1.365^{* *} \\
(0.691)\end{array}$ & $\begin{array}{l}-0.253 \\
(0.676)\end{array}$ & $\begin{array}{l}1.091 * \\
(0.590)\end{array}$ & $\begin{array}{c}0.430 \\
(0.432)\end{array}$ \\
\hline 5.ciri_physint & $\begin{array}{l}-0.532 \\
(0.766)\end{array}$ & $\begin{array}{c}-1.894 * * * \\
(0.705)\end{array}$ & $\begin{array}{l}-0.705 \\
(0.688)\end{array}$ & $\begin{array}{c}0.891 \\
(0.616)\end{array}$ & $\begin{array}{l}0.0165 \\
(0.443)\end{array}$ \\
\hline 6.ciri_physint & $\begin{array}{l}-1.267 \\
(0.798)\end{array}$ & $\begin{array}{c}-1.979 * * * \\
(0.744)\end{array}$ & $\begin{array}{l}-0.981 \\
(0.699)\end{array}$ & $\begin{array}{c}0.662 \\
(0.640)\end{array}$ & $\begin{array}{l}0.0355 \\
(0.469)\end{array}$ \\
\hline 7.ciri_physint & $\begin{array}{l}-1.690 * \\
(0.894)\end{array}$ & $\begin{array}{c}-2.364 * * * \\
(0.847)\end{array}$ & $\begin{array}{l}-1.155 \\
(0.745)\end{array}$ & $\begin{array}{c}0.689 \\
(0.664)\end{array}$ & $\begin{array}{l}-0.511 \\
(0.508)\end{array}$ \\
\hline 8.ciri_physint & $\begin{array}{c}-2.785^{* *} \\
(1.089)\end{array}$ & $\begin{array}{c}-3.101 * * * \\
(1.012)\end{array}$ & $\begin{array}{c}-1.766 * * \\
(0.805)\end{array}$ & $\begin{array}{c}0.240 \\
(0.723)\end{array}$ & $\begin{array}{c}-1.027 * \\
(0.554)\end{array}$ \\
\hline 2.system_d & $\begin{array}{c}3.036^{* * *} \\
(1.054)\end{array}$ & $\begin{array}{c}2.007 * * \\
(0.992)\end{array}$ & $\begin{array}{c}2.582^{* * *} * \\
(0.810)\end{array}$ & $\begin{array}{c}2.870 * * * \\
(0.761)\end{array}$ & $\begin{array}{c}3.536 * * * \\
(0.632)\end{array}$ \\
\hline 3.system_d & $\begin{array}{c}5.218 * * * \\
(0.961)\end{array}$ & $\begin{array}{c}2.701 * * * \\
(0.730)\end{array}$ & $\begin{array}{c}4.364 * * * \\
(0.897)\end{array}$ & $\begin{array}{c}2.525^{* * *} * \\
(0.765)\end{array}$ & $\begin{array}{c}3.803 * * * \\
(0.548)\end{array}$ \\
\hline log_unna_gdp & $\begin{array}{c}16.88 * * * \\
(1.607)\end{array}$ & $\begin{array}{c}17.17 * * * \\
(1.487)\end{array}$ & $\begin{array}{c}15.91 * * * \\
(1.083)\end{array}$ & $\begin{array}{c}17.31 * * * \\
(1.004)\end{array}$ & $\begin{array}{c}14.67 * * * \\
(0.766)\end{array}$ \\
\hline Observations & 1,346 & 1,479 & 2,425 & 2,641 & 3,057 \\
\hline
\end{tabular}


O passo final foi rodar os modelos xtlogit com a função beta (ver tabela 4). Como a variável dependente é binária, não podemos interpretar a magnitude dos coeficientes de uma maneira direta, como fazemos na análise de regressão linear. Nesse sentido, para visualizarmos quais variáveis impactam mais nas variáveis dependentes, precisamos rodar o modelo com a função beta.

Tabela 4: Teste beta para todos os tratados - esttab FE1 FE2 FE3 FE4 FE5, beta

\begin{tabular}{|c|c|c|c|c|c|}
\hline & $\begin{array}{r}(1) \\
\text { ecosoc }\end{array}$ & $\begin{array}{r}\text { (2) } \\
\text { civpol }\end{array}$ & $\begin{array}{c}\text { (3) } \\
\text { cedaw }\end{array}$ & $\begin{array}{r}(4) \\
\text { tortura }\end{array}$ & $\begin{array}{r}(5) \\
\text { crian }\end{array}$ \\
\hline \multicolumn{6}{|l|}{ main } \\
\hline emil & $\begin{array}{l}-3.511 * * * \\
(-5.02)\end{array}$ & $\begin{array}{l}-2.680 * \star \star \\
(-4.28)\end{array}$ & $\begin{array}{l}-1.402^{\star \star} \\
(-3.26)\end{array}$ & $\begin{array}{l}-1.523 * * * \\
(-3.87)\end{array}$ & $\begin{array}{l}-1.969 * \star \star \\
(-5.95)\end{array}$ \\
\hline democracy & $\begin{array}{l}6.630^{* * *} \\
(5.91)\end{array}$ & $\begin{array}{l}10.934 * * * \\
(8.21)\end{array}$ & $\begin{array}{l}5.199 * * * \\
(6.43)\end{array}$ & $\begin{array}{l}3.963^{* * *} \\
(6.86)\end{array}$ & $\begin{array}{l}5.376^{* * *} \\
(9.33)\end{array}$ \\
\hline agedem & $\begin{array}{r}0.987 \\
(0.95)\end{array}$ & $\begin{array}{l}4.272 \star * \star \\
(4.17)\end{array}$ & $\begin{array}{l}7.376^{* \star *} \\
(7.52)\end{array}$ & $\begin{array}{r}1.766 \\
(1.93)\end{array}$ & $\begin{array}{l}4.649 * * * \\
(6.66)\end{array}$ \\
\hline allhouse & $\begin{array}{r}-0.954 \\
(-1.48)\end{array}$ & $\begin{array}{l}-0.671 \\
(-1.18)\end{array}$ & $\begin{array}{r}-0.783 \\
(-1.33)\end{array}$ & $\begin{array}{l}-1.252 * \star \star \\
(-3.38)\end{array}$ & $\begin{array}{l}-0.955^{* *} \\
(-2.65)\end{array}$ \\
\hline 0.ciri_phy t & $\begin{array}{r}0.000 \\
(.)\end{array}$ & $\begin{array}{r}0.000 \\
(.)\end{array}$ & $\begin{array}{r}0.000 \\
(.)\end{array}$ & $\begin{array}{r}0.000 \\
(.)\end{array}$ & $\begin{array}{r}0.000 \\
(.)\end{array}$ \\
\hline 1.ciri_phy t & $\begin{array}{c}0.796 \\
(1.94)\end{array}$ & $\begin{array}{l}-0.188 \\
(-0.51)\end{array}$ & $\begin{array}{r}0.015 \\
(0.04)\end{array}$ & $\begin{array}{r}0.413 \\
(1.53)\end{array}$ & $\begin{array}{r}0.217 \\
(0.96)\end{array}$ \\
\hline 2.ciri_phy $\sim t$ & $\begin{array}{l}1.045^{\star} \\
(2.02)\end{array}$ & $\begin{array}{l}-0.189 \\
(-0.41)\end{array}$ & $\begin{array}{l}-0.049 \\
(-0.12)\end{array}$ & $\begin{array}{r}0.582 \\
(1.76)\end{array}$ & $\begin{array}{r}0.398 \\
(1.60)\end{array}$ \\
\hline 3.ciri_phy $\sim t$ & $\begin{array}{r}0.673 \\
(1.29)\end{array}$ & $\begin{array}{l}-0.451 \\
(-1.01)\end{array}$ & $\begin{array}{l}-0.040 \\
(-0.09)\end{array}$ & $\begin{array}{r}0.578 \\
(1.60)\end{array}$ & $\begin{array}{r}0.345 \\
(1.31)\end{array}$ \\
\hline 4.ciri_phy t & $\begin{array}{l}-0.066 \\
(-0.11)\end{array}$ & $\begin{array}{l}-1.075^{*} \\
(-1.98)\end{array}$ & $\begin{array}{l}-0.207 \\
(-0.37)\end{array}$ & $\begin{array}{r}0.785 \\
(1.85)\end{array}$ & $\begin{array}{r}0.311 \\
(0.99)\end{array}$ \\
\hline 5.ciri_phy t & $\begin{array}{r}-0.424 \\
(-0.69)\end{array}$ & $\begin{array}{l}-1.502 \text { * } \\
(-2.69)\end{array}$ & $\begin{array}{l}-0.581 \\
(-1.02)\end{array}$ & $\begin{array}{r}0.631 \\
(1.45)\end{array}$ & $\begin{array}{r}0.012 \\
(0.04)\end{array}$ \\
\hline 6.ciri_phy t & $\begin{array}{r}-0.920 \\
(-1.59)\end{array}$ & $\begin{array}{l}-1.406^{* *} \\
(-2.66)\end{array}$ & $\begin{array}{r}-0.801 \\
(-1.40)\end{array}$ & $\begin{array}{r}0.465 \\
(1.03)\end{array}$ & $\begin{array}{r}0.025 \\
(0.08)\end{array}$ \\
\hline 7.ciri_phy t & $\begin{array}{r}-0.994 \\
(-1.89)\end{array}$ & $\begin{array}{l}-1.515^{* *} \\
(-2.79)\end{array}$ & $\begin{array}{r}-0.973 \\
(-1.55)\end{array}$ & $\begin{array}{r}0.529 \\
(1.04)\end{array}$ & $\begin{array}{l}-0.385 \\
(-1.01)\end{array}$ \\
\hline 8.ciri_phy t & $\begin{array}{l}-1.575^{*} \\
(-2.56)\end{array}$ & $\begin{array}{l}-1.841 * * \\
(-3.06)\end{array}$ & $\begin{array}{l}-1.449 * \\
(-2.20)\end{array}$ & $\begin{array}{r}0.181 \\
(0.33)\end{array}$ & $\begin{array}{l}-0.766 \\
(-1.85)\end{array}$ \\
\hline 1.system_d & $\begin{array}{r}0.000 \\
(.)\end{array}$ & $\begin{array}{r}0.000 \\
(.)\end{array}$ & $\begin{array}{r}0.000 \\
(.)\end{array}$ & $\begin{array}{r}0.000 \\
(.)\end{array}$ & $\begin{array}{r}0.000 \\
(.)\end{array}$ \\
\hline 2.system_d & $\begin{array}{l}2.802 * * \\
(2.88)\end{array}$ & $\begin{array}{l}1.877 * \\
(2.02)\end{array}$ & $\begin{array}{l}2.920 * * \\
(3.19)\end{array}$ & $\begin{array}{l}2.794 * \star \star \\
(3.77)\end{array}$ & $\begin{array}{l}3.545^{* \star *} \\
(5.60)\end{array}$ \\
\hline 3.system_d & $\begin{array}{l}5.422 * \star * \\
(5.43)\end{array}$ & $\begin{array}{l}2.785 * * * \\
(3.70)\end{array}$ & $\begin{array}{l}5.050 * * * \\
(4.87)\end{array}$ & $\begin{array}{l}2.582 * \star * \\
(3.30)\end{array}$ & $\begin{array}{l}3.964 * * * \\
(6.94)\end{array}$ \\
\hline $\log _{\text {lonna_gdp }}$ & $\begin{array}{l}68.704 * * * \\
(10.50)\end{array}$ & $\begin{array}{l}72.990 * * * \\
(11.55)\end{array}$ & $\begin{array}{l}76.437 * * * \\
(14.69)\end{array}$ & $\begin{array}{l}76.672 * * * \\
(17.25)\end{array}$ & $\begin{array}{l}65.233^{* * *} \\
(19.14)\end{array}$ \\
\hline $\mathrm{N}$ & 1346 & 1479 & 2425 & 2641 & 3057 \\
\hline
\end{tabular}


O resultado exposto na tabela 4 mostra que a variável independente que mais impacta nos seis modelos é a variável DEMOCRACY. Esse dado confirma empiricamente a tese defendida pelos teóricos da Paz Democrática, já que o regime político é um fator determinante do comportamento do Estado no plano internacional. Neste caso, as democracias aderem mais aos regimes internacionais de direitos humanos.

Em relação à maturidade do sistema democrático, a variável AGEDEM apresentou magnitude pequena, mas este dado era esperado, uma vez que ela é uma variável contínua, que varia de 1 a 139, com média de 32,3. Portanto, apesar da intensidade ser pequena, a média de idade dos regimes políticos do banco de dados é relativamente elevada, aumentando o impacto dessa variável na adesão aos seis tratados de direitos humanos considerados.

Por fim, o impacto da variável controle também é significativo nos seis modelos analisados. Indicando que o tamanho do PIB (LOG_UNNA_GDP) do Estado é um fator peremptório na adesão aos regimes internacionais de direitos humanos. 


\section{Conclusão da análise quantitativa}

A adesão aos regimes internacionais de direitos humanos tem como fator determinante o tipo de regime político que o Estado possui. Essa é a conclusão que chegamos após analisar cinco diferentes tratados internacionais de direitos humanos: desde os tratados fundadores da ONU, como o Pacto Internacional dos Direitos Econômicos, Sociais e Culturais de 1966 e o Pacto Internacional de Direitos Civis e Políticos de 1966. Até os que protegem direitos de minorias históricas, como a Convenção sobre a Eliminação de Todas as Formas de Discriminação contra a Mulher (CEDAW) de 1979, e a Convenção do Direito das Crianças de 1989. Por fim, a Convenção contra a tortura e outros tratamentos ou penas cruéis, desumanos ou degradantes de 1984 também é analisada.

A principal característica que influencia na adesão a esses cinco regimes é se o Estado é um regime democrático. Esse achado traz novas sustentações empíricas à teoria da Paz Democrática. Sendo assim, comprovamos estatisticamente que o comportamento das democracias é de fato mais cooperativo se comparados ao comportamento das autocracias no plano internacional.

Essa dissertação também pode comprovar parcialmente que as conclusões do Vreeland (2008) não podem ser expandidas para todos os tratados de direitos humanos, como ele havia indagado. Isso porque a existência de polarização política (ALLHOUSE) no regime só é estatisticamente significativa para a Convenção contra a tortura e a Convenção Direito das Crianças.

Todavia, seria interessante em uma pesquisa futura separar as democracias e as autocracias e rodar um modelo para cada tipo de regime político. Dessa forma, poderíamos observar quais características dentro de cada regime influenciam mais na adesão aos regimes internacionais de direitos humanos. Por fim, um outro passo importante seria desenvolver estudos de caso para se detalhar melhor a dinâmica doméstica das variáveis que influenciam o comportamento estatal no plano internacional. 


\section{Referências Bibliográficas}

BAYEFSKY, Anne F. The UN human rights treaty system: Universality at the crossroads. The Hague, The Netherlands: Kluwer Law International. 2001.

BRYSK, Alison. From Above and Below: Social Movements, the International System, and Human Rights in Argentina. Comparative Political Studies, 26 (3), pp. 259-285, 1993.

CARDENAS, Sonia. Norm Collision: Explaining the Effects of International Human Rights Pressure on State Behavior. International Studies Review, vol. 6, no. 2 (June), pp. 213-231, 2004.

. Conflict and Compliance: State Responses to International Human

Rights Pressure. Philadelphia: University of Pennsylvania Press, 2007.

CHRISTENSEN, Thomas J. Useful Adversaries: Grand Strategy, Domestic Mobilization, and Sino-American Conflict, 1947-1958. Princeton: Princeton University Press, 1996.

EVANS, Peter B. et al. Bringing the State Back In, Cambridge University Press, 1985.

EVANS, Peter B., JACOBSON, Harold K., PUTNAM, Robert D., Double-Edged Diplomacy: International Bargaining and Domestic Politics. Berkeley: University of California Press. 1993.

FASS, Paula S. A Historical Context for the United Nations Convention on the Rights of the Child. The ANNALS of the American Academy of Political and Social Science. vol. 633 no. 1 pp.17-29, 2011.

FRANKLIN, James C. Shame on You: The Impact of Human Rights Criticism on Political Repression in Latin America. International Studies Quarterly, 52, pp. 187-211, 2008.

FRIEDBERG, Aaron L. The weary titan: Britain and the experience of relative decline, 1895-1905. Princeton, NJ: Princeton University Press, 1988. 
HAFNER-BURTON, Emilie M. e TSUTSUI, Kiyoteru. Human rights in a globalizing world: The paradox of empty promises. American Journal of Sociology, 111, pp. 13731411, 2005.

HAFNER-BURTON, E.; MANSFIELD, E.; PEVEHOUSE, J. Democratization and Human Rights Regimes. Paper apresentado na reunião da International Studies Association (ISA), 2008.

HATHAWAY, Oona A. Do Human Rights Treaties Make a Difference?. The Yale Law Journal, vol. 111, n.8, pp. 1935-2042, 2002.

Why Do Countries Commit to Human Rights Treaties?. Journal of Conflict Resolution, vol. 51, n.4, pp. 588-621, 2007.

HUNTINGTON, Samuel P. The Third Wave: Democratization in the Late Twentieth Century. Volume 4 of Julian J. Rothbaum distinguished lecture series. Oklahoma: University of Oklahoma Press, 1993.

KHAGRAM, Sanjeev; RIKER, James V.; SIKKINK, Kathryn. From Santiago to Seattle: transational advocay groups restructuring world politics, in Restructuring World Politics. Transnational social movements, networks and norms, University of Minnesota Press, pp. 3-23, 2002.

KECK, Margaret; SIKKINK, Kathryn. Activists Beyond Borders: Advocacy Networks in International Politics. Ithaca and London: Cornell University Press, 1998.

KEOHANE, Robert O. Theory of world politics: structural realism and beyond. Neorealism and its Critics, v. 158, p. 190-97, 1986.

LANDMAN, T. Protecting Human Rights: A Comparative Study. Washington, DC: Georgetown Univ. Press, 2005.

LANDMAN, Todd; CARVALHO, Edzia. Measuring Human Rights. New York, NY: Routledge, 2010.

LEFFLER, Melvyn P. A Preponderance of Power: National Security, the Truman Administration, and the Cold War. Stanford: Stanford University Press, 1992. 
LIPPMAN, Matthew. The Development and Drafting of the United Nations Convention Against Torture and Other Cruel Inhuman or Degrading Treatment or Punishment. 17 B.C. Int'l \& Comp. L. Rev. pp. 275-335, 1994.

MANSFIELD, Edward.; PEVEHOUSE, Jon C. Democratization and International Organizations. International Organization, 60, Winter, pp.137-167, 2006.

Democratization and the Varieties of International Organizations. Journal of Conflict Resolution, 52, pp. 269-294, 2008.

MORAVCSIK, Andrew. The origins of human rights regimes: Democratic delegation in postwar Europe. International Organization, v. 54, n. 02, p. 217-252, 2000.

MEARSHEIMER, John J. Structural Realism. pp. 71-88. In DUNNE, T.; KURKI, M. \& SMITH, S. International Relations Theories: Discipline and Diversity. Oxford: Oxford University Press, 2007.

NEUMAYER, Eric. Do international human rights treaties improve respect for human rights? Journal of conflict resolution, v. 49, n. 6, p. 925-953, 2005.

ONUKI, Janina. $O$ elo entre regimes políticos domésticos e adesão a regimes internacionais. São Paulo: Centro de Estudos das Negociações Internacionais, USP, 2013.

POWELL, Emilia Justyna; STATON, Jeffrey K. Domestic Judicial Institutions and Human Rights Treaty Violation. International Studies Quarterly, 53, pp. 149-174, 2009.

POWELL, Robert. Absolute and relative gains in international relations theory. The American Political Science Review, pp. 1303-1320, 1991.

RISSE, Thomas; ROPP, Stephen C \& SIKKINK, Kathryn. The Power of Human Rights: International Norms and Domestic Change. Cambridge: Cambridge University Press, 1999.

ROSE, Gideon. Neoclassical realism and theories of foreign policy. World politics, v. 51, n. 01, p. 144-172, 1998.

SIKKINK, Kathryn. Human rights, principled issue-networks, and sovereignty in Latin America. International Organization, v. 47, n. 03, p. 411-441, 1993. 
SIKKINK, Kathryn. The justice cascade: how human rights prosecutions are changing world politics. New York: W. W. Norton \& Co. 2011

SIMMONS, Beth A. Mobilizing for Human Rights: International Law in Domestic Politics. New York: Cambridge University Press, 2009.

Treaty Compliance and Violation. Annual Review of Political Science, vol. 13, pp. 273-296, 2010.

WALTZ, Kenneth N. Theory of International Politics. New York: McGraw-Hill, 1979. A response to my critics. pp. 27-130. In KEOHANE, Robert Owen (org.). Neorealism and its Critics. New York: Columbia University Press, 1986.

WENDT, Alexander. Anarchy is what states make of it: the social construction of power politics. International organization, v. 46, n. 02, p. 391-425, 1992.

WIIK, R. Democratization in the name of civil society: A quantitative analysis of the impact of nongovernment organizations on democratization. Norwegian University of Science and Technology, 2002. http://www.sv.ntnu.no/iss/Robert.Wiik/thesis.pdf.

WOHLFORTH, William C. The Elusive Balance: Power and Perceptions During the Cold War. Cornell University Press, 1993.

VREELAND, James R. Political Institutions and Human Rights: Why Dictatorships Enter into the United Nations Convention Against Torture. International Organization v. 62, n. 01, pp. 65-101, 2008.

ZAKARIA, Fareed. From Wealth to Power: The Unusual Origins of Americas World Role. Princeton: Princeton University Press, 1998. 


\section{Apêndice I: Codebook}

\section{COUNTRY}

Variável categoria nominal que identifica o país, segundo o código da base de dados do Correlates of War (COW).

Acesso em: http://www.correlatesofwar.org/COW\%20State\%20list.xls

\section{YEAR}

Variável que indica o ano da observação, podendo variar entre 1966 e 2012.

\section{ECOSOC}

\section{Aderiu (1), Não Aderiu (0)}

O país ratificou (1) o Pacto Internacional dos Direitos Econômicos, Sociais e Culturais de 1966 ou não ratificou (0).

Acesso em: https://treaties.un.org/pages/ViewDetails.aspx?src=TREATY\&mtdsg_no=IV-

$\underline{3 \& \text { chapter }=4 \& \text { lang }=\text { en }}$

\section{CIVPOL}

\section{Aderiu (1), Não Aderiu (0)}

O país ratificou (1) o Pacto Internacional dos Direitos Civis e Políticos de 1966 ou não ratificou (0).

Acesso em:

https://treaties.un.org/pages/ViewDetails.aspx?src=TREATY\&mtdsg_no=IV-4\&chapter=4\&lang=en 


\section{CEDAW}

Aderiu (1), Não Aderiu (0)

O país ratificou (1) a Convenção sobre a Eliminação de Todas as Formas de Discriminação contra a Mulher de 1979 ou não ratificou (0).

Acesso em:

https://treaties.un.org/pages/ViewDetails.aspx?src=TREATY\&mtdsg no=IV-8\&chapter=4\&lang=en

\section{TORTURA}

\section{Aderiu (1), Não Aderiu (0)}

O país ratificou (1) a Convenção contra a Tortura e Outros Tratamentos ou Penas Cruéis, Desumanos ou Degradantes de 1984 ou não ratificou (0).

Acesso em:

https://treaties.un.org/pages/ViewDetails.aspx?src=TREATY\&mtdsg no=IV-9\&chapter=4\&lang=en

\section{CRIAN}

\section{Aderiu (1), Não Aderiu (0)}

O país ratificou (1) a Convenção sobre os Direitos da Criança de 1989 ou não ratificou $(0)$.

Acesso em:

https://treaties.un.org/pages/ViewDetails.aspx?src=TREATY\&mtdsg_no=IV-11\&chapter=4\&lang=en

\section{EMIL}

O governante efetivo é militar (1) ou não é militar (0)

Variável binária que identifica se o governante efetivo é ou já foi um militar profissional (1) ou se é civil (0). Período de análise: 1946-2008

*(Bangladesh em 2008 estava codificada como 2, dado foi alterado para missing, uma vez que não há explicação no codebook da base de dados do Cheibub e Gandhi para o valor 2).

Acesso em: https://uofi.box.com/shared/static/bba3968d7c3397c024ec.dta 


\section{DEMOCRACY}

\section{Democracia (1), Autocracia (0)}

Variável binária que identifica a natureza do regime político do país. Esta variável foi retirada do banco de dados Democracy and Dictatorship construída por José Antonio Cheibub, Jennifer Gandhi e James Raymond Vreeland. Período de análise: Período de análise: 1946-2008

Acesso em: https://uofi.box.com/shared/static/bba3968d7c3397c024ec.dta

\section{AGEDEM}

Variável contínua que calcula a idade em anos do presente regime político classificado como Democracia. Período de análise: 1946-2008 (quando aplicado, o período de análise foi estendido: 1870-2008).

Acesso em: https://uofi.box.com/shared/static/bba3968d7c3397c024ec.dta

\section{ALLHOUSE}

Partido político da situação: tem maioria absoluta no legislativo (1), não tem maioria absoluta (0)

Variável binária que classifica se o partido político tem maioria absoluta nas esferas que tem capacidade de criar leis (houses that have lawmaking powers). Período de análise: 1975-2012

Acesso em: Database of Political Institutions 2012 (updated Jan. 2013) http://econ.worldbank.org/WBSITE/EXTERNAL/EXTDEC/EXTRESEARCH/0,,contentMDK:20649465 pagePK:64214825 piPK:64214943 theSitePK:469382,00.html 


\section{CIRI_PHYSINT}

Variável categórica ordinal construída a partir da soma de outras quatro variáveis que variam de 0 a 2 e avaliam: tortura (CIRI_TORT), mortes extrajudiciais (CIRI_KILL), detenção de políticos (CIRI_POLPRIS) e desaparecimentos (CIRI_DISAP). Portanto esse índice pode variar e de 0 (o governo não respeita nenhum desses quatro direitos) até 8 (o governo respeita esses quatro direitos). Período de análise: 1981-2007.

Acesso em: http://www.nsd.uib.no/macrodataguide/set.html?id=3\&sub=1

\section{SYSTEM_D}

Sistema Presidencialista (3), Sistema parlamentarista (2), Assembleia elege Presidente (1)

Variável categórica que indica a natureza do sistema político do país. Período de análise: $1975-2012$

Acesso em: Database of Political Institutions 2012 (updated Jan. 2013) http://econ.worldbank.org/WBSITE/EXTERNAL/EXTDEC/EXTRESEARCH/0,,contentMDK:20649465 pagePK:64214825 piPK:64214943 theSitePK:469382,00.html

\section{LOG_UNNA_GDP}

Logaritmo de uma variável contínua que mede o PIB (produto interno bruto) do país a preço constante de 2005 em dólares estadunidenses. Período de análise: 1970-2011 Acesso em: http://unstats.un.org/unsd/snaama/dnltransfer.asp?fID=6 


\section{Apêndice II - Sumário do Banco de Dados}

\begin{tabular}{|c|c|c|c|c|c|}
\hline Variable & Obs & Mean & Std. Dev. & Min & $\operatorname{Max}$ \\
\hline year & 8977 & 1989 & 13.56542 & 1966 & 2012 \\
\hline ecosoc & 7789 & .5577096 & .4966903 & 0 & 1 \\
\hline civpol & 7789 & .557838 & .4966754 & 0 & 1 \\
\hline cedaw & 7789 & .5570677 & .4967645 & 0 & 1 \\
\hline tortura & 7789 & .3592245 & .4798039 & 0 & 1 \\
\hline crian & 7789 & .5121325 & .4998849 & 0 & 1 \\
\hline emil & 7072 & .2200226 & .4142909 & 0 & 1 \\
\hline democracy & 7073 & .4479005 & .4973134 & 0 & 1 \\
\hline agedem & 7073 & 32.34356 & 31.4141 & 1 & 139 \\
\hline sys tem_d & 6110 & 2.44108 & .6925803 & 1 & 3 \\
\hline allhouse & 5106 & .5936154 & .4912061 & 0 & 1 \\
\hline ciri_physint & 4624 & 4.922145 & 2.333533 & 0 & 8 \\
\hline log_unna_gdp & 7140 & 23.16046 & 2.424723 & 15.73139 & 30.21124 \\
\hline
\end{tabular}

